\title{
The use of a wave boundary layer model in SWAN
}

\author{
Du, Jianting; Bolaños, Rodolfo; Larsén, Xiaoli Guo
}

Published in:

Journal of Geophysical Research: Oceans

Link to article, DOI:

10.1002/2016JC012104

Publication date:

2017

Document Version

Peer reviewed version

Link back to DTU Orbit

Citation (APA):

Du, J., Bolaños, R., \& Larsén, X. G. (2017). The use of a wave boundary layer model in SWAN. Journal of Geophysical Research: Oceans, 122(1), 42-62. https://doi.org/10.1002/2016JC012104

\section{General rights}

Copyright and moral rights for the publications made accessible in the public portal are retained by the authors and/or other copyright owners and it is a condition of accessing publications that users recognise and abide by the legal requirements associated with these rights.

- Users may download and print one copy of any publication from the public portal for the purpose of private study or research.

- You may not further distribute the material or use it for any profit-making activity or commercial gain

- You may freely distribute the URL identifying the publication in the public portal

If you believe that this document breaches copyright please contact us providing details, and we will remove access to the work immediately and investigate your claim. 


\title{
The use of a wave boundary layer model in SWAN
}

\author{
Jianting Du ${ }^{1 *}$, Rodolfo. Bolaños ${ }^{2}$, Xiaoli Guo Larsén ${ }^{1}$ \\ ${ }^{1}$ Department of Wind Energy, Technical University of Denmark, Ris $\varnothing$ Campus, Roskilde, Denmark \\ ${ }^{2}$ DHI, Agern Allé 5, DK-2970 Hørsholm, Denmark
}

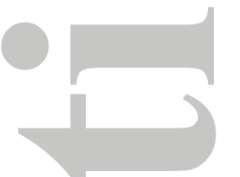

\section{Key Points:}

- A wave boundary layer model is implemented in SWAN as a new wind-input source function

- The WBLM is based on the momentum and kinetic energy conservation and it provides reliable wind stress estimation

- The new WBLM wind-input source improves the wave simulations in idealized fetchlimited studies

* This study is funded by the Danish Forskel project X-WiWa (PSO-12020).

Corresponding author: Jianting Du, jitdedtu.dk

This article has been accepted for publication and undergone full peer review but has not been through the copyediting, typesetting, pagination and proofreading process which may lead to differences between this version and the Version of Record. Please cite this article as doi: 10.1002/2016JC012104

(C) 2016 American Geophysical Union

Received: Jun 28, 2016; Revised: Nov 03, 2016; Accepted: Nov 30, 2016 


\section{Abstract}

A Wave Boundary Layer Model (WBLM) is implemented in the third-generation ocean wave model SWAN to improve the wind-input source function under idealized, fetch-limited condition. Accordingly, the white capping dissipation parameters are re-calibrated to fit the new wind-input source function to parametric growth curves. The performance of the new pair of wind-input and dissipation source functions is validated by numerical simulations of fetch-limited evolution of wind-driven waves. As a result, fetch-limited growth curves of significant wave height and peak frequency show close agreement with benchmark studies at all wind speeds $\left(5 \sim 60 \mathrm{~ms}^{-1}\right)$ and fetches $(1 \sim 3000 \mathrm{~km})$. The WBLM wind-input source function explicitly calculates the drag coefficient based on the momentum and kinetic energy conservation. The modeled drag coefficient using WBLM wind-input source function is in rather good agreement with field measurements. Thus, the new pair of wind-input and dissipation source functions not only improve the wave simulation but also have the potential of improving air-sea coupling systems by providing reliable momentum flux estimation at the air-sea interface.

\section{Introduction}

Momentum flux at the air-sea interface is important for wind and wave simulations in providing the lower boundary for atmospheric models and influencing the wind-input source functions for spectral ocean wave models. The momentum flux is usually described by surface roughness length $\left(z_{0}\right)$ or drag coefficient $\left(C_{d}\right)$. In the last five decades, numerous studies have been focused on parameterizing $z_{0}$ and $C_{d}$ through wind and wave parameters such as 10 -meters wind speed $\left(u_{10}\right)$, inverse wave age $\left(u_{*} / c_{p}\right)$, wave steepness $\left(H_{m 0} / L_{p}\right)$ etc. [e.g. Wu, 1982; Taylor and Yelland, 2001; Zijlema et al., 2012; Edson et al., 2013]. Such kind of parameterizations are often empirically based on limited measurements that do not represent the overall complexity of the wind and wave conditions, especially during storms or in coastal areas.

An alternative, theoretical approach of calculating $z_{0}$ and $C_{d}$ is through the momentum conservation within the wave boundary layer (WBL). That is, at the lower part of the atmospheric boundary layer, the total wind stress is constant with height and it is equal to the sum of wave-induced stress (form stress) and turbulence stress. Such kind of methods were first introduced by Janssen et al. [1989] and further developed by Janssen [1991], Chalikov and Makin [1991], Makin et al. [1995], Hara and Belcher [2002, 2004], and Moon et al. [2004]. Among them, Janssen [1991] successfully developed a wind-wave coupling approach that has been 
widely applied in many ocean wave models as wind-input source functions, such as the WAve Model (WAM) [Komen et al., 1996], Simulating WAves Nearshore (SWAN) [Booij et al., 1999], WAVEWATCH III [Tolman and Chalikov, 1996], and MIKE 21 SW [Sørensen et al., 2004].

However, it has been reported that Janssen [1991] overestimates the wind stress in strongwind conditions e.g. [Jensen et al., 2006]. The overestimation of wind stress at high wind speeds was also found in WAVEWATCH III by using other wind-input source terms according to Moon et al. [2004, 2009]. In order to avoid this, Jensen et al. [2006] introduced a cap to limit $u_{*} / u_{10}$ to be in the range of $0.05 \sim 0.06$. Ardhuin et al. [2010] added a maximum value of $z_{0}$ as 0.0015 $m$ in Janssen [1991] wind-input source function to reduce possible unrealistic wind stresses at high winds. Alternatively, a spectral sheltering mechanism was introduced to reduce the windinput at high frequencies [e.g. Banner and Morison, 2010]. The spectral sheltering mechanism describes that longer waves absorb the turbulent stress from wind so that the growth of shorter waves is reduced in the existence of longer waves [Chen and Belcher, 2000]. In the last three decades, the sheltering mechanism has been discussed, observed, and verified by many studies [e.g. Makin and Mastenbroek, 1996; Kudryavtsev et al., 1999; Chen and Belcher, 2000; Hara and Belcher, 2002; Makin et al., 2007]. One effort of introducing sheltering effect to the windinput source function was carried out by Banner and Morison [2010], who, instead of using the total stress in Janssen [1991] wind-input source function, used the reduced stress which equals to the total stress minus the wave-induced stress accounting for the cumulative effect of wave number contribution. It was shown that the growth rate of high frequency waves was reduced due to the sheltering effect. Another attempt of introducing the sheltering effect is by using a Wave Boundary Layer Model (WBLM) [Makin and Mastenbroek, 1996; Hara and Belcher, 2002, 2004; Moon et al., 2004]. The WBLM not only takes into account of the momentum conservation and sheltering effect, but also makes sure that the turbulent kinetic energy (TKE) conserves at all levels in the WBL. The WBLM has been used by several studies [e.g. Moon et al., 2004, 2009; Reichl et al., 2014]. Moon et al. [2009] showed that the use of reduced $C_{d}$ estimated from a WBLM [Moon et al., 2004] in WAVEWATCH III [Tolman and Chalikov, 1996] improves the wave simulations during hurricanes. More recently, Chen and $Y u$ [2016] improved Moon et al. [2004] WBLM by including the energy dissipation due to the presence of sea spray under idealized tropical cyclones.

The main objective of the present study is to improve the third-generation ocean wave model SWAN under fetch-limited conditions on wave simulation and stress estimation by introducing the WBLM to the Janssen [1991] wind-input source function. It should be pointed 
out that in the previous studies in the literature [e.g. Moon et al., 2004, 2009; Reichl et al., 2014;

Chen and $Y u, 2016]$, the WBLM was used to calculate the surface stress, but was not used as a wind-input source function for the wave model, and therefore the wave growth within the WBLM was not consistent with the wave growth in the wave model. Thus, the momentum loss from the atmosphere is not exactly the same as the momentum gained by the waves. In this study, the WBLM and SWAN share the same wind-input source function, thus ensuring the momentum flux is consistent. Accordingly, the white capping dissipation parameters are re-calibrated to reproduce the fetch limited wave growth curves under a wide range of wind conditions.

\section{Background}

In SWAN, the evolution of the wave spectrum is governed by the action balance equation. In deep water condition, it can be written as:

$$
\frac{d N}{d t}=S_{i n}+S_{n l}+S_{d s}
$$

where $N(\sigma, \theta, \vec{x}, t)=\phi / \sigma$ is the action density spectrum, $\phi(\sigma, \theta, \vec{x}, t)$ is the energy density spectrum. $\sigma, \theta, \vec{x}, t$ are the radian frequency, wave direction, spatial coordinate, and time respectively. On the right hand side of equation (1) are the three source terms of wind-wave generation and dissipation: wave growth by the wind $S_{i n}$, non-linear four-wave interaction $S_{n l}$, and wave dissipation due to white capping $S_{d s}$. In this study, we focus on the momentum exchange at the air-sea interface. Thus $S_{i n}$ will be investigated in details in Section 3.1. Accordingly, $S_{d s}$ will then be modified (Section 3.2) to balance $S_{i n}$ to ensure the wave evolution to be consistent with benchmark fetch-limited wave growth studies [e.g. Kahma and Calkoen, 1992; Young, 1999] (hereafter KC92, Y99). The method for solving the $S_{n l}$ will be discussed in Section 4.

\subsection{Wind-input source function $S_{i n}$}

The wind-input source function is described as the growth rate multiplied by the action density spectrum, $S_{i n}=\beta_{g}(\sigma, \theta) N(\sigma, \theta)$. In this study, three expressions for the wave growth $\left(\beta_{g}\right)$ in SWAN 41.01 [The SWAN Team, 2015] are used. One follows Komen et al. [1984] (hereafter KOM):

$$
\beta_{g}(\sigma, \theta)=0.25 \sigma \frac{\rho_{a}}{\rho_{w}}\left(28 \frac{u_{*}}{c} \cos \left(\theta-\theta_{w}\right)-1\right)
$$


where $\rho_{a}$ and $\rho_{w}$ are the air and water density, respectively, $c$ is the phase velocity, $u_{*}$ is the friction velocity, $\theta_{w}$ is the wind direction. The wave model is driven by the wind speed at 10 $\mathrm{m}\left(u_{10}\right)$ above the mean sea level. $u_{10}$ is transformed into $u_{*}$ through the drag relation:

$$
u_{*}^{2}=C_{d} u_{10}^{2}
$$

where $C_{d}$ is the drag coefficient at $10 \mathrm{~m}$. According to Zijlema et al. [2012]:

$$
C_{d}=\left(0.55+2.97 \widetilde{u}-1.49 \widetilde{u}^{2}\right) \times 10^{-3}
$$

where $\widetilde{u}=u_{10} / u_{\text {ref }}, u_{\text {ref }}=31.5 \mathrm{~ms}^{-1}$.

The second expression for $\beta_{g}$ follows Janssen [1991] (hereafter JANS):

$$
\beta_{g}(\sigma, \theta)=C_{\beta} \sigma \frac{\rho_{a}}{\rho_{w}}\left(\frac{u_{*}}{c}\right)^{2} \cos ^{2}\left(\theta-\theta_{w}\right)
$$

where $C_{\beta}$ is the Miles constant, and it is described as a function of the non-dimensional critical height $\lambda$ :

$$
\begin{aligned}
C_{\beta} & =\frac{J}{\kappa^{2}} \lambda \ln ^{4} \lambda, \lambda \leq 1, \text { where } \\
\lambda & =\frac{g z_{0}}{c} e^{r}, r=\kappa c / u_{*}\left|\cos \left(\theta-\theta_{w}\right)\right|
\end{aligned}
$$

where $\kappa=0.41$ is the von Kármán constant, $g$ is the gravity acceleration and $J=1.2$ is a constant. JANS wave growth rate expression implicitly takes into account of the wave impact to the air-sea momentum flux through a wind-wave coupling approach. In this approach, it is first assumed that in neutral condition the wind profile above the sea surface keeps a logarithmic shape, and the roughness length above the sea surface is parameterized by Charnock relation [Charnock, 1958]:

$$
u_{z}=\frac{u_{*}}{\kappa} \ln \left(\frac{z}{z_{0}}\right), z_{0}=\alpha u_{*}^{2} / g
$$

where $\alpha$ is the Charnock parameter. Janssen [1991] described the Charnock parameter to be dependent on the wave-induced stress $\left(\vec{\tau}_{w}\right)$ :

$$
\alpha=\alpha_{0}\left(1-\frac{\vec{\tau}_{w}}{\vec{\tau}_{t o t}}\right)^{-1 / 2}, \alpha_{0}=0.01
$$

where $\vec{\tau}_{t o t}$ is the surface total wind stress, and $\vec{\tau}_{w}$ is obtained from the integration of windinput source function:

$$
\vec{\tau}_{w}=\rho_{w} \int_{0}^{\infty} \int_{-\pi}^{\pi} \sigma^{2} S_{i n} \frac{\vec{k}}{k} d \theta d \sigma
$$

where $k$ is the wavenumber. The drag relation can thus be derived from equations (7) and (8), and the total stress could be calculated from $10 \mathrm{~m}$ wind speed through $u_{*}=\sqrt{C_{d}} u_{10}$, where 
the drag coefficient:

$$
C_{d}=\left[\kappa / \ln \left(10 / z_{0}\right)\right]^{2}
$$

Relating equation (7) to (9) results in a stress table where $\vec{\tau}_{t o t}$ is a function of $u_{10}$ and $\vec{\tau}_{w}$. It should be noted that the original algorithm of SWAN for calculating the stress table would cause numerical errors. In this study, this problem is solved by introducing the algorithm from WAM (https://github.com/mywave/WAM) to SWAN. A more detailed description of this is given in Appendix A.

A third choice of the wind-input source function is implemented by van der Westhuysen et al. [2007] (hereafter WES). The expression of WES wind-input source function is based on the laboratory and field observations [e.g. Plant, 1982] that for strong wind forcing $\left(u_{*} / c>\right.$ 0.1) $\beta_{g}$ is proportional to $\left(u_{*} / c\right)^{2}$, which is similar to JANS; whereas for weaker wind forcing $\left(u_{*} / c<0.1\right) \beta_{g}$ is proportional to $u_{*} / c$, which is similar to KOM. Through an analytical fit to the experimental dataset of Snyder et al. [1981] and Plant [1982], Yan [1987] proposed the following expression for the growth rate:

$$
\beta_{g}(\sigma, \theta)=D\left(\frac{u_{*}}{c}\right)^{2} \cos \left(\theta-\theta_{w}\right)+E\left(\frac{u_{*}}{c}\right) \cos \left(\theta-\theta_{w}\right)+F \cos \left(\theta-\theta_{w}\right)+H
$$

van der Westhuysen et al. [2007] refitted equation (11) to better match Snyder et al. [1981]'s expression for mature waves, and the following parameter values are used: $D=4.0 \times 10^{-5}$, $E=5.52 \times 10^{-3}, F=5.2 \times 10^{-5}, H=-3.02 \times 10^{-4}$.

\subsection{White capping dissipation source function $S_{d s}$}

Over the last decade, efforts have been put to include physical parameters such as breaking probability, the dissipation rate per unit area etc. in the dissipation source term [e.g. Ardhuin et al., 2010; Banner and Morison, 2010; Filipot and Ardhuin, 2012; Leckler et al., 2013]. However, since the main objective of the present study is to improve the wind-input source function in SWAN, in this study, we use the standard white capping dissipation expression of Komen et al. [1984], which could be written as:

$$
S_{d s}(\sigma, \theta)=-C_{d s}\langle\sigma\rangle\left(\langle k\rangle^{2} m_{0}\right)^{2}\left[(1-\Delta) \frac{k}{\langle k\rangle}+\Delta\left(\frac{k}{\langle k\rangle}\right)^{2}\right] \phi(\sigma, \theta)
$$

where $\langle\sigma\rangle$ and $\langle k\rangle$ are the mean wave radian frequency and mean wave number respectively, with $\langle\sigma\rangle=m_{0} / \iint \sigma^{-1} \phi(\sigma, \theta) d \theta d \sigma$ and $\langle k\rangle=\left[m_{0} / \iint k^{-1 / 2} \phi(\sigma, \theta) d \theta d \sigma\right]^{2}$, where $m_{0}=\iint \phi(\sigma, \theta) d \theta d \sigma$ is the total wave energy. $C_{d s}$ and $\Delta$ are dissipation parameters that should be calibrated for each particular wind-input source function. For KOM $S_{i n}$ (equation 2), $C_{d s}=2.5876, \Delta=1$; for JANS $S_{i n}$ (equation 5 ), $C_{d s}=4.5, \Delta=0.5$. 
Dissipation source function of WES for deep water is written as:

$$
S_{d s}(\sigma, \theta)=-C_{d s}\left(\frac{B(k)}{B_{r}}\right)^{p / 2} \sqrt{g k} \phi(\sigma, \theta)
$$

where $B(k)=\int(d \sigma / d k) \cdot k^{3} \phi(\sigma, \theta) d \theta$ is the azimuthal-integrated spectral saturation, $B_{r}=$

$1.75 \times 10^{-3}$ is a threshold saturation level, and $C_{d s}=5.0 \times 10^{-5}$ is a dissipation coeffi-

cient. The exponent $p$ is given by Alves and Banner [2003]:

$$
p=\frac{p_{0}}{2}+\frac{p_{0}}{2} \tanh \left[10\left(\sqrt{\frac{B(k)}{B_{r}}}-1\right)\right]
$$

where $p_{0}(\sigma)=3+\tanh \left[26\left(u_{*} / c-0.1\right)\right]$.

\section{Methodology}

\subsection{WBLM and the modified wind-input source function}

In this study, the WBLM as developed by Hara and Belcher [2004] and Moon et al. [2004] is implemented to modify the JANS wind-input source function. The WBLM is based on the momentum conservation at the lower part of atmospheric boundary layer above the sea surface, the Wave Boundary Layer. The total stress $\vec{\tau}_{t o t}(z)$ is constant with height within WBL and equals to the sum of the turbulent stress $\vec{\tau}_{t}(z)$ and wave-induced stress $\vec{\tau}_{w}(z)$ :

$$
\vec{\tau}_{\text {tot }}(z)=\vec{\tau}_{t}(z)+\vec{\tau}_{w}(z)=\text { constant }
$$

The wave induced stress is expressed as:

$$
\vec{\tau}_{w}(z)=\rho_{w} \int_{\sigma_{m i n}}^{\sigma_{z}} \int_{-\pi}^{\pi} \beta_{g}(\sigma, \theta) \sigma^{2} N(\sigma, \theta) \frac{\vec{k}}{k} d \theta d \sigma
$$

where $\sigma_{z}=\sqrt{g \delta / z}, \delta=0.01$ [Moon et al., 2004], $\sigma_{\min }$ is the minimum radian frequency of the wave spectrum. Equation (16) means that the wave-induced stress at height $z$ is equal to the integration of momentum flux to the waves within the range of $\sigma_{\min }<\sigma<\sigma_{z}$. Con-

sidering the sheltering mechanism that the turbulent wind stress near the sea surface is reduced by low frequency waves, the turbulent stress can be expressed by the combination of equations (15) and (16):

$$
\vec{\tau}_{t}(z)=\vec{\tau}_{t o t}-\rho_{w} \int_{\sigma_{m i n}}^{\sigma_{z}} \int_{-\pi}^{\pi} \beta_{g}(\sigma, \theta) \sigma^{2} N(\sigma, \theta) \frac{\vec{k}}{k} d \theta d \sigma
$$

According to the sheltering mechanism, the turbulent stress rather than total stress contributes to the wave growth. Thus, in this study, the growth rate function is expressed as a modified 
JANS (equation 5) which is proportional to the local friction velocity $u_{*}^{l}=\sqrt{\left|\overrightarrow{\tau_{t}}(z) / \rho_{a}\right|}$ in-

stead of the total friction velocity, $u_{*}$ :

$$
\beta_{g}(\sigma, \theta)=C_{\beta} \sigma \frac{\rho_{a}}{\rho_{w}}\left(\frac{u_{*}^{l}}{c}\right)^{2} \cos ^{2}\left(\theta-\theta_{w}\right)
$$

The constant $J$ in equation (6) is changed to 1.6 according to Banner and Morison [2010] instead of the original of 1.2 in Janssen [1991].

The wind profile within the wave boundary layer is calculated from the kinetic energy conservation equation:

$$
\frac{d}{d z}\left(\vec{u} \cdot \vec{\tau}_{t o t}\right)+\frac{d \Pi}{d z}+\frac{d \Pi^{\prime}}{d z}-\rho_{a} \varepsilon=0
$$

where $u$ is the mean wind speed, $\Pi$ and $\Pi^{\prime}$ are the vertical transport of the kinetic energy due to the wave-induced motions and the vertical transport of TKE, respectively, and $\varepsilon$ is the viscous dissipation of TKE. It is assumed that the wave-induced vertical transport of kinetic energy is mainly from the pressure transport [Hara and Belcher, 2004], which is equal to the energy flux into the surface waves:

$$
\Pi(z)=\int_{\sigma_{m i n}}^{\sigma} \tilde{F}_{w}(\sigma) d \sigma
$$

where $\tilde{F}_{w}$ is the vertical decay function:

$$
\tilde{F}_{w}(\sigma)=\rho_{w} \int_{-\pi}^{\pi} \beta_{g}(\sigma, \theta) g \sigma N(\sigma, \theta) d \theta
$$

The viscous dissipation rate is parameterized as in [Hara and Belcher, 2004]:

$$
\varepsilon(z)=\frac{\left|\vec{\tau}_{t}(z) / \rho_{a}\right|^{\frac{3}{2}}}{\kappa z}
$$

Assuming that the gradient of the vertical transport of the TKE, $d \Pi^{\prime} / d z$, is small compared to the other terms [Hara and Belcher, 2004], the wind profile near the sea surface can be expressed as:

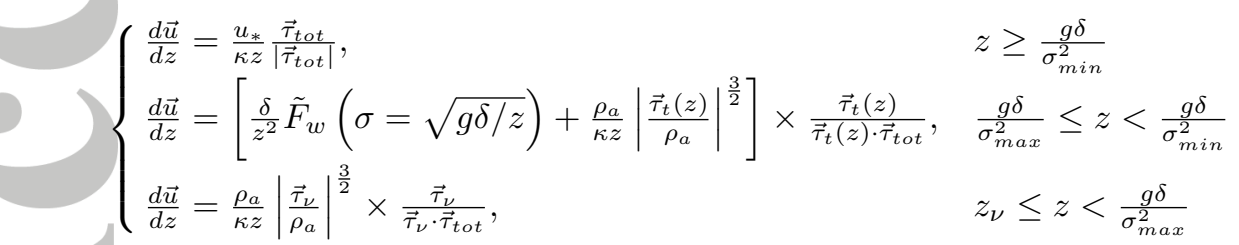

where $z_{\nu}=0.1 \frac{\nu_{a}}{\sqrt{\left|\vec{\tau}_{\nu} / \rho_{a}\right|}}$ is the roughness length of the viscous sublayer where the wind speed turns into zero, and $\nu_{a}$ is the air viscosity.

The calculation of WBLM starts with an initial estimation of $\vec{\tau}_{t o t}$, and it calculates $S_{i n}$, $\vec{\tau}_{w}$, and $\vec{\tau}_{t}$ at each frequency (height) by equations (16) to (18), and then calculates the wind profile by equation (23). The process repeats using the Newton-Raphson method until the wind 
speed at the reference height $z_{r e f}$ calculated from equation (23) equals to the provided wind speed. In this paper, we use $z_{r e f}=10 \mathrm{~m}$. The efficiency of WBLM is highly related to how many iterations it takes. During the experiments, most of the cases took 4 to 6 iterations to find the solution, and the maximum number of iteration was set to 20 .

\subsection{Re-calibration of dissipation source function}

When $S_{i n}$ is modified, the dissipation parameters in $S_{d s}$ as described in Section 2.2, $C_{d s}$ and $\Delta$, also need to be re-calibrated to make sure that the fetch-limited wave generation experiments are consistent with benchmark studies. It is found that with constant $C_{d s}$ and $\Delta$, the slop of the fetch-limited wave growth curves are too low compared with the benchmark studies of KC92 and Y99. Babanin et al. [2010] introduced an approach based on the physical constraints that the ratio of $S_{i n}$ and $S_{d s}$ could be described as a function of the wave development stage. The relation of $S_{i n}$ and $S_{d s}$ can be written as:

$$
\int S_{d s}(\sigma) d \sigma=R_{d s} \int S_{i n}(\sigma) d \sigma
$$

where $R_{d s}$ is the ratio of the dissipation integral to the input integral. In Babanin et al. [2010], $R_{d s}$ is parameterized as a function of inverse wave age $u_{10} / c_{p}$. However, with this parameterization, the WBLM as implemented in SWAN cannot reproduce the benchmark fetch-limited wave growth curves of KC92 and Y99. Therefore, in this study, $R_{d s}$ is described as:

$$
\begin{cases}R_{d s}=1-0.15\left(\frac{10}{u_{10}}\right)^{\frac{1}{2}} \cdot \max \left[1.0,1.53\left(\frac{5.2 \times 10^{-7}}{\widetilde{E}}\right)^{\frac{1}{4}}\right], & \widetilde{E} \leq \widetilde{E}_{P M} \\ R_{d s}=1, & \widetilde{E} \geq \widetilde{E}_{P M}\end{cases}
$$

where $\widetilde{E}=m_{0} g^{2} / u_{10}^{4}$ is non-dimensional energy; $\widetilde{E}_{P M}=3.64 \times 10^{-3}$ is the Pierson-Moskowitz limit [Pierson and Moskowitz, 1964] (PM64). The details of the calculation of $R_{d s}$ are given in Appendix B.

The new dissipation source function reads:

$$
S_{d s}^{+}(\sigma)=\frac{R_{d s} \int S_{i n}(\sigma) d \sigma}{\int S_{d s}(\sigma) d \sigma} S_{d s}(\sigma)
$$

where $S_{d s}$ is calculated from equation (12). Equation (26) can only modify the integrated magnitude of $S_{d s}$ which is controlled by $C_{d s}$. However, the spectral distribution in the high frequency range which is controlled by $\Delta$ still needs to be adjusted. Based on the tests of $\Delta$ in the range from 0 to $1, \Delta=0.1$ is chosen so that the balance of the source functions maintain a $f^{-4}$ high frequency spectral tail for deep water condition following the arguments of van der Westhuysen et al. [2007]. 


\subsection{Diagnostic part of the wave spectrum}

Wave models such as WAM solves the action density spectrum within a frequency range

around the peak $\sigma_{\min } \leq \sigma \leq \sigma_{c}$ using the action balance equation (equation 1). $\sigma_{\min }$ is the minimum radian frequency, and $\sigma_{c}$ is the cut-off frequency. In WAM $\sigma_{c}=\min \left(2.5\langle\sigma\rangle, \sigma_{\max }\right)$, where $\langle\sigma\rangle$ is the mean frequency and $\sigma_{\max }$ is the maximum frequency. Beyond $\sigma_{c}$, a high frequency tail must be specified. SWAN uses a different approach than WAM, the cut-off frequency in SWAN is always the same as the maximum frequency $\left(\sigma_{c}=\sigma_{\max }\right)$. The high frequency tail is solved diagnostically using a standard power spectra shape $\phi(\sigma, \theta)=R_{h} \sigma^{-5}$. $R_{h}$ is a coefficient that is determined so that the diagnostic part of the wave spectrum has a smooth transition to the rest of the spectrum:

$$
R_{h}=\phi\left(\sigma_{c}, \theta\right) \sigma_{c}^{5}=N\left(\sigma_{c}, \theta\right) \sigma_{c}^{6}
$$

At frequencies higher than $\sigma_{c}$, the action density spectrum is solved by:

$$
N(\sigma, \theta)=R_{h} \sigma^{-6}=N\left(\sigma_{c}, \theta\right)\left(\frac{\sigma_{c}}{\sigma}\right)^{6}
$$

In the calculation of WBLM, a high frequency tail is also needed for the integration of wave stresses $\left(\tau_{w}\right)$. The high frequency tail is proven to not only affect the wave spectrum evolution but also have a strong impact on the estimation of the drag coefficient [Reichl et al., 2014].

To avoid the constraint of the parameterized high frequency tail, in this study, the cut-off frequency is setup to $10.5 \mathrm{~Hz}$ so that the source terms are calculated for a wide range of frequencies. The sensitivity of WBLM to the choice of cut-off frequency is discussed in Section 6.

\section{Experiment design}

In this section, numerical experiments of fetch-limited wave evolution done in this study are described. Such type of experiments have earlier been used by many to calibrate and validate the performance of spectral wave models when new source terms were introduced [e.g. Komen et al., 1984; Alves and Banner, 2003; van der Westhuysen et al., 2007; Gagnaire-Renou et al., 2011]. The general idea of such experiments is to simulate the wave evolution along the fetch under constant offshore wind in deep water condition. The wind direction is perpendicular to a straight coastline. Fetch-limited wave evolution has been extensively investigated through field and laboratory measurements [e.g. Hasselmann et al., 1973; Kahma and Calkoen, 1992; Hwang and Wang, 2004; Young, 1999]. The evolution of wave energy and peak frequency over 
fetch can be described by the following two dimensionless relations [e.g. Young, 1999]:

$$
\left\{\begin{array}{l}
\widetilde{E}=A_{e} \widetilde{x}^{B_{e}} \\
\widetilde{F_{p}}=A_{f} \widetilde{x}^{B_{f}}
\end{array}\right.
$$

where $\widetilde{F_{p}}=f_{p} u_{10} / g$ is non-dimensional peak frequency and $\widetilde{x}=x g / u_{10}^{2}$ is non-dimensional fetch. $A_{e}, B_{e}, A_{f}, B_{f}$ are parameters in the corresponding energy-fetch and frequency-fetch relationship. In this study we choose the parameters from the benchmark studies of Kahma and Calkoen [1992] (Composite, $A_{e}=5.2 \times 10^{-7}, B_{e}=0.9, A_{f}=2.18, B_{f}=-0.27$ ) and Young [1999] $\left(A_{e}=7.5 \times 10^{-7}, B_{e}=0.8, A_{f}=2.0, B_{f}=-0.25\right)$. It should be noted that the benchmark studies normally apply to $u_{10} \leq 25 \mathrm{~ms}^{-1}$ and $\mathrm{x} \leq 300 \mathrm{~km}$ due to lack of measurements at higher wind speeds and longer fetches. Here we linearly extend them to higher wind speed and longer fetches to investigate if the WBLM also applies to storm conditions. Both storm conditions and fetch-limited waves have very young waves that dominate the surface stress. Extending the benchmark studies to higher wind speeds and longer fetches is debatable, however the estimates of drag with the WBLM for those winds have shown to be within the measured range as shown in Section 5.4.

The one-dimensional SWAN model is used for the fetch-limited study. The spatial distribution of resolution $(\Delta \mathrm{x})$ is set as follows. For fetch between 0 and $20 \mathrm{~km}, \Delta \mathrm{x}=100 \mathrm{~m}$; between $20 \mathrm{~km}$ and $100 \mathrm{~km}, \Delta \mathrm{x}=400 \mathrm{~m}$; between $100 \mathrm{~km}$ and $300 \mathrm{~km}, \Delta \mathrm{x}=1 \mathrm{~km}$; between $300 \mathrm{~km}$ and $1000 \mathrm{~km}, \Delta \mathrm{x}=4 \mathrm{~km}$; between $1000 \mathrm{~km}$ and $3000 \mathrm{~km}, \Delta \mathrm{x}=10 \mathrm{~km}$. The frequency dimension of the wave spectrum ranges from $0.01 \mathrm{~Hz}$ to $10.5 \mathrm{~Hz}$ with geometric progression, $f_{n+1} / f_{n}=1.1$ giving a total number of frequencies of 73 . When using JANS $S_{i n}$, the cut-off frequency $\left(f_{c}\right)$ varies with wind speed to make sure that the simulation remains numerically stable. $f_{c}$ grows linearly from $0.45 \mathrm{~Hz}$ to $3.0 \mathrm{~Hz}$ for wind speed decreasing from $30 \mathrm{~ms}^{-1}$ to $5 \mathrm{~ms}^{-1}$; for $u_{10}>30 \mathrm{~ms}^{-1}, f_{c}=0.45 \mathrm{~Hz}$. The directional dimension of the wave spectrum utilizes 36 directions with a constant spacing of $10^{\circ}$. The wind speeds at 10 $\mathrm{m}$ are set to constant values between 5 to $60 \mathrm{~ms}^{-1}$. The simulations initiate from JONSWAP spectrum with local wind speed and $100 \mathrm{~m}$ fetch. It runs for 72 hours with a time step of 1 min until the model reaches an equilibrium state. Note that, the combination of very large wind and very long fetch (e.g. $u_{10}$ of $60 \mathrm{~ms}^{-1}$ and fetch $x$ of more than $500 \mathrm{~km}$ ) is mostly of academic interest only.

Four different wind-input source functions are used in the experiments: KOM (equation 2), JANS (equation 5), WES [van der Westhuysen et al., 2007], and the one developed here, WBLM (equation 18). For $S_{\text {in }}$ with KOM, JANS, and WES, the corresponding dissipation pa- 

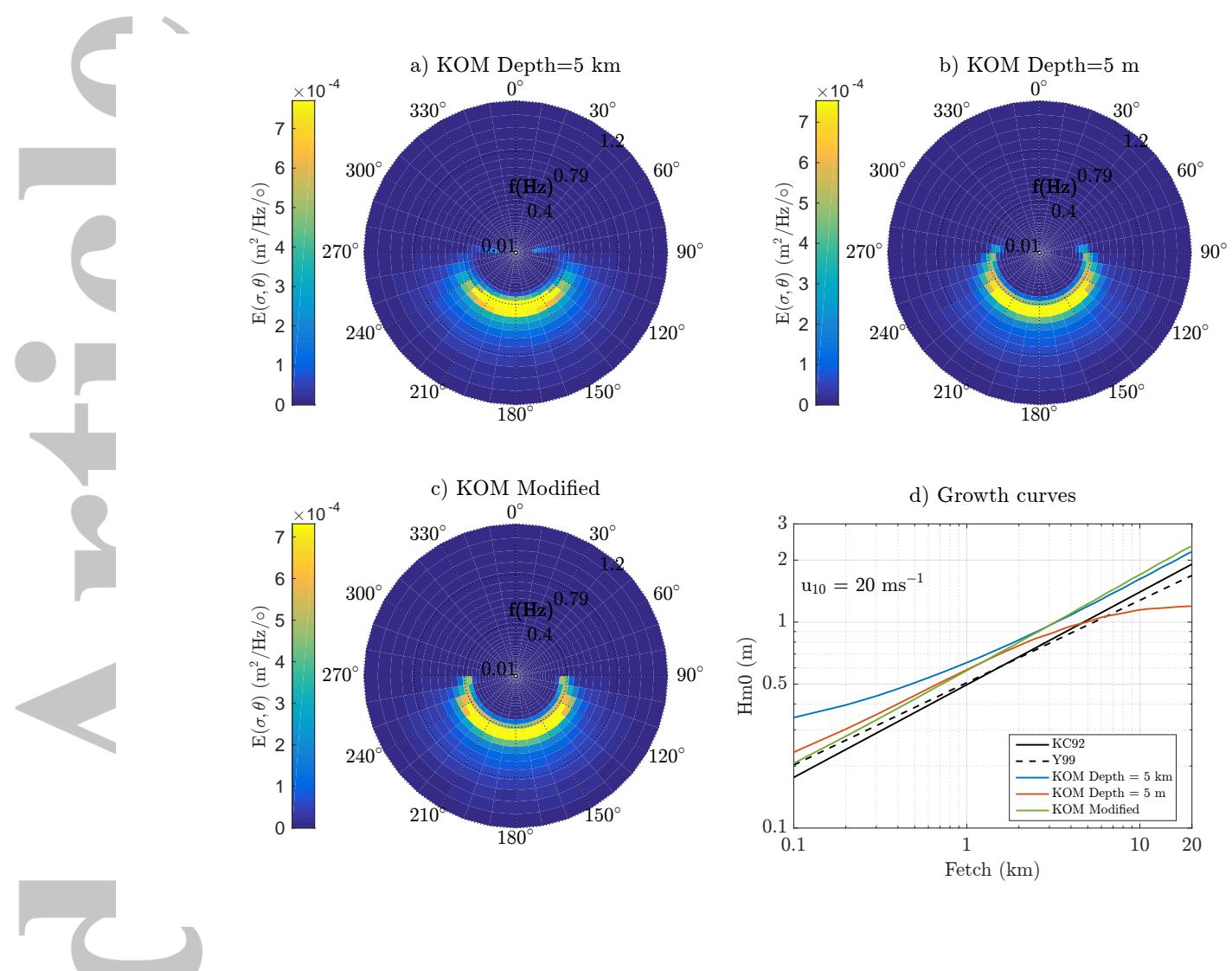

Figure 1. Two dimensional wave spectra in SWAN using KOM option with wind speed of $20 \mathrm{~ms}^{-1}$ at fetch $\mathrm{x}=1 \mathrm{~km}$ after 72 hours simulation. Sub-figure a) is in deep water condition (depth $=5 \mathrm{~km}$ ); sub-figure $\mathrm{b})$ is in shallow water condition (depth $=5 \mathrm{~m}$ ); sub-figure c) is in deep water after the modification with $N(\theta, \sigma)=0$ for $\left|\theta-\theta_{w}\right|>90^{\circ}$; sub-figure d) is the significant wave height as a function of fetch in those three cases.

rameters use the standard setups as described in Section 2.2. For $S_{i n}$ with WBLM, the dissipation parameters are described by equation (25) and (26).

In this study, it is found that using KOM in deep water condition, for fetches $x \leq 5$ $\mathrm{km}$, energy of the wave spectrum spreads too wide in direction space. Thus, it results in some extra energy that propagate against the wind in the low frequency part of the wave spectrum (for both 1D and 2D SWAN version). This phenomenon is clearly seen in Figure 1 a) that in deep water condition (depth $=5 \mathrm{~km}$ ), with $u_{10}=20 \mathrm{~ms}^{-1}$ and wind direction at $180^{\circ}$, after 72 hours simulation, at $1 \mathrm{~km}$ fetch there is energy at directions $\theta<90^{\circ}$ and $\theta>270^{\circ}$ at low frequencies. JANS, WES, and WBLM have similar phenomenon, but since the directional spreading seems much narrower, the extra energy is much smaller and negligible. An additional test with $\mathrm{KOM}$ in shallower water condition was done using a water depth of $5 \mathrm{~m}$ and the extra energy in low frequencies disappeared (Figure $1 \mathrm{~b}$ ). Thus in real cases, such a phe- 


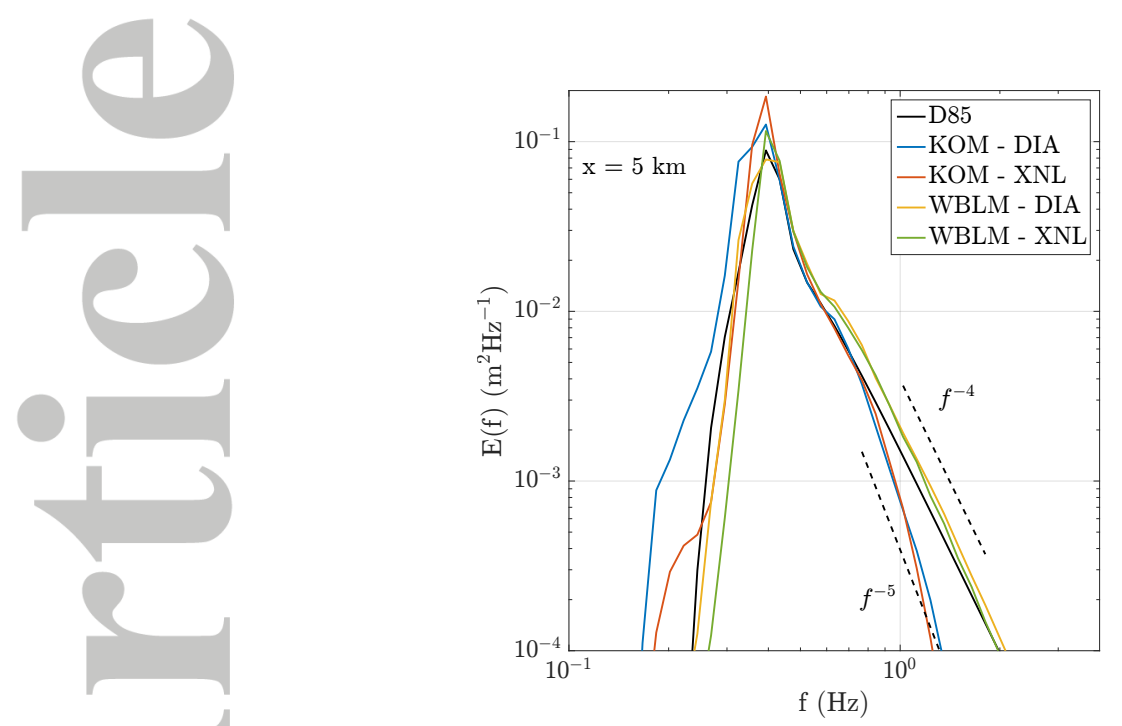

Figure 2. Wave spectra calculated by KOM and WBLM $S_{i n}$ with DIA and XNL $S_{n l}$ methods. The black solid lines are calculated from Donelan et al. [1985] with $f_{p}$ estimated from Kahma and Calkoen [1992].

nomenon rarely happens since the near shore waters are mostly shallow. In this study, we use the idealized deep water condition, so that it is necessary to remove the unrealistic extra low frequency waves that propagate against the wind. We introduced a directional limiter that for wave direction $\left|\theta-\theta_{w}\right|>90^{\circ}, N(\theta, \sigma)=0$. The corresponding wave spectrum is shown in Figure $1 \mathrm{c})$. Figure $1 \mathrm{~d})$ presents the growth curves of significant height $\left(H_{m 0}=4 \sqrt{m_{0}}\right)$ as a function of fetch in kilometer. It is seen that after introducing the directional limiter, the extra energy in short fetches is removed and the growth curves are closer to the benchmark studies of KC92 and Y99.

There are two methods in SWAN to solve the non-linear four-wave interactions in deep water. One is the Discrete Interaction Approximation (DIA) method [Hasselmann and Hasselmann, 1985], the other is a more exact method (XNL) which solves the original six-dimensional Boltzmann integral formulation [van Vledder, 2006]. Both the DIA and XNL methods are tested for KOM and WBLM for short fetches. The wave spectra at $x=5 \mathrm{~km}$ after 24 hours of simulation are shown in Figure 2. The difference in the spectra between XNL and DIA $S_{n l}$ methods at the high frequencies is significantly smaller than the difference between KOM and WBLM $S_{i n}$ methods. The computation time of XNL method is about 200 times the DIA method during this experiment. Considering the small difference in the spectra and huge difference in the computation time, the DIA method was chosen for the other experiments in this study. 


\section{Results}

\subsection{Fetch-limited wind-wave growth}

Figure 3 shows $H_{m 0}$ as a function of fetch, with $10 \mathrm{~m}$ wind speed $u_{10}=5$ to $60 \mathrm{~ms}^{-1}$ presented in the sub-figures. In each panel, the benchmark wave evolution curves and the results from our experiments with different $S_{i n}$ (KOM, JANS, WES, and WBLM) are compared. Table 5.1 presents the deviation of $H_{m 0}$ from the KC92 curves which were calculated from the numerical experiments with wind-input source function tested. For each wind speed and fetch category, the values of smallest deviation are shown in bold text.

For $15 \mathrm{~ms}^{-1} \leq u_{10} \leq 40 \mathrm{~ms}^{-1}$, KOM tends to overestimate $H_{m 0}$. The overestimation increases with wind speed, and it reaches about $2 \mathrm{~m}$ for $u_{10}=40 \mathrm{~ms}^{-1}$. This is consistent with the results presented by Huang et al. [2013], that SWAN using Wu [1982] $C_{d}$ with a cap of $C_{d} \leq 2 \times 10^{-3}$ tends to overestimate the maximum $H_{m 0}$ in the deep Gulf of Mexico.

For $u_{10} \geq 15 \mathrm{~ms}^{-1}$, JANS significantly overestimates $H_{m 0}$, the overestimation increases with wind speed and fetch. This is consistent with Jensen et al. [2006]'s results which show overestimation of $H_{m 0}$ in extreme winds if a cap on the drag coefficient $\left(C_{d}^{\max }=3.6 \times 10^{-3}\right)$ is not applied to JANS. There is a clear discontinuity in JANS growth curve around $x=50$ $\mathrm{km}$ because the change in action density between two iterations is limited by Hersbach and Janssen [1999] limiter.

For $15 \mathrm{~ms}^{-1} \leq u_{10} \leq 50 \mathrm{~ms}^{-1}$, WES overestimates $H_{m 0}$ about $0.1 \sim 1 \mathrm{~m}$ in short fetches. This is consistent with the study of Bottema and van Vledder [2009], showing persistent overestimations of $H_{m 0}$ with WES for short fetches.

The green lines in Figure 3 and the bold text in Table 5.1 show that the results of WBLM closely reproduce the KC92 curves for most wind speeds and fetches. Its good performance does not vary with wind speeds and fetches, except the underestimation of $H_{m 0}$ at very high wind speed and very long fetches, namely $u_{10}>50 \mathrm{~ms}^{-1}$ and $x>500 \mathrm{~km}$. Nevertheless, its value is still between the KC92 and Y99 curves.

Figure 4 shows the peak wave frequency $f_{p}$ as a function of fetch. For $u_{10}=5 \mathrm{~ms}^{-1}$, the original options of KOM, JANS, and WES in SWAN tend to underestimate $f_{p}$ for fetches $\mathrm{x} \leq 1 \mathrm{~km}$, and overestimate $f_{p}$ for $\mathrm{x} \geq 10 \mathrm{~km}$. For $10 \mathrm{~ms}^{-1} \leq u_{10} \leq 50 \mathrm{~ms}^{-1}$, KOM gives close agreement with the benchmark studies; WES and JANS underestimate $f_{p}$ for short fetches; the underestimation of JANS is larger than WES, and it is proportional with the wind speed. It is also clearly seen that WBLM gives the best agreement with KC92 for most of the cases, 

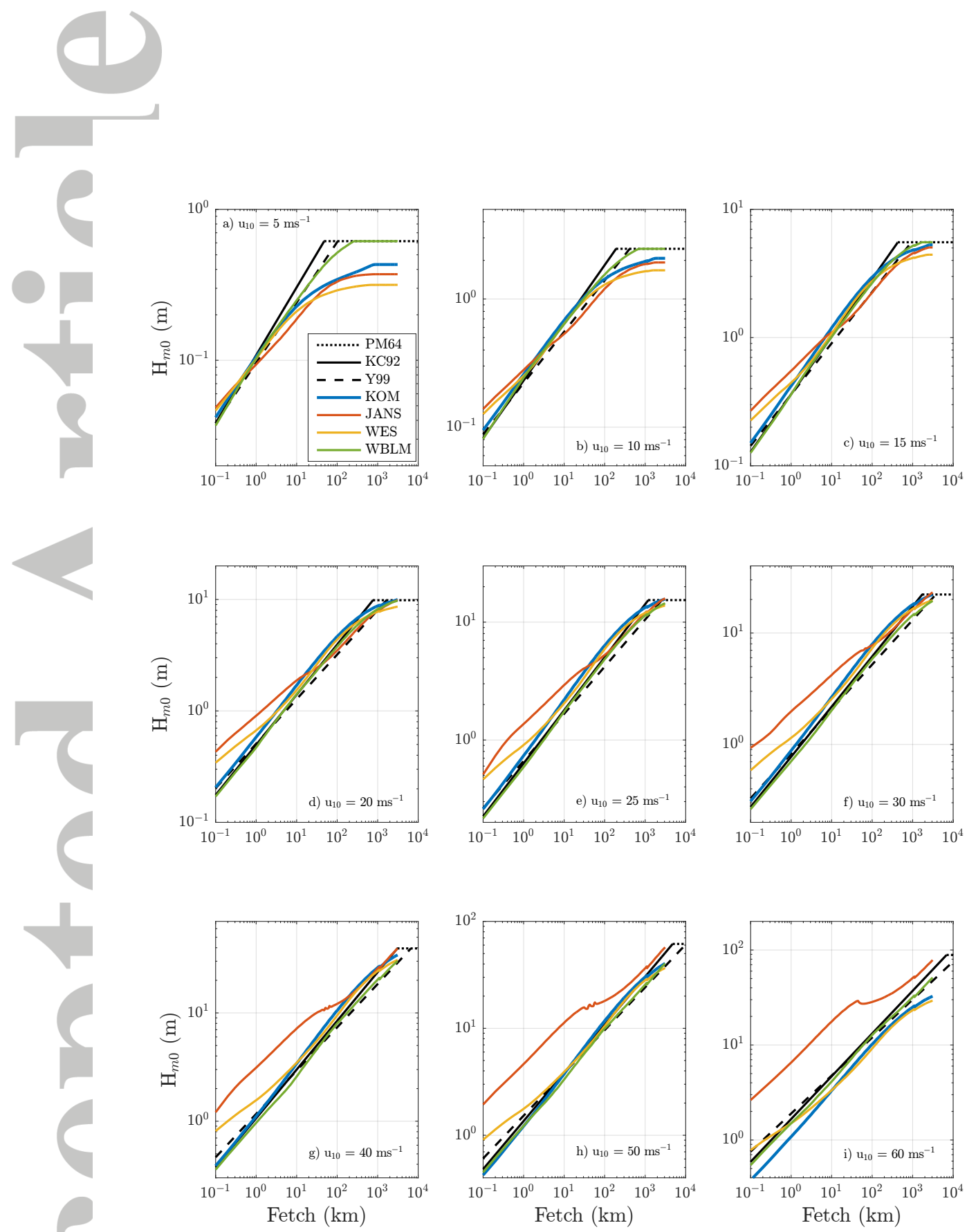

Figure 3. Significant wave height $H_{m 0}$ as a function of fetch for $10 \mathrm{~m}$ wind speed $u_{10}$ from 5 to $60 \mathrm{~ms}^{-1}$ presented in panels. The black solid and black dashed lines are from the benchmark studies of Kahma and Calkoen [1992] and Young [1999], respectively. The colored lines represent the results of the numerical experiments with wind-input source functions of KOM, JANS, WES, and WBLM, respectively. 
Table 1. The deviation of $H_{m 0}(\mathrm{~m})$ from KC92 curves calculated from the numerical experiments with wind-input source functions of KOM, JANS, WES, and WBLM, respectively. The columns and rows are fetches and wind speeds respectively. In each wind speed and fetch, the values of smallest deviation are shown in bold text.

\begin{tabular}{|c|c|c|c|c|c|c|c|c|}
\hline Fetch (km) & $10^{0}$ & $10^{1}$ & $10^{2}$ & $5 \times 10^{2}$ & $10^{0}$ & $10^{1}$ & $10^{2}$ & $5 \times 10^{2}$ \\
\hline $10\left(\mathrm{~ms}^{-1}\right)$ & \multicolumn{4}{|c|}{$H_{m 0}(\mathrm{KOM}-\mathrm{KC} 92)(\mathrm{m})$} & \multicolumn{4}{|c|}{$H_{m 0}(\mathrm{JANS}-\mathrm{KC} 92)(\mathrm{m})$} \\
\hline 5 & -0.003 & -0.077 & -0.273 & -0.207 & -0.014 & -0.117 & -0.284 & -0.247 \\
\hline 10 & 0.027 & 0.029 & -0.409 & -0.625 & 0.048 & -0.118 & -0.636 & -0.721 \\
\hline 20 & 0.086 & 0.303 & 0.718 & -0.480 & 0.408 & 0.479 & -0.456 & -1.695 \\
\hline 30 & 0.105 & 0.477 & 1.781 & 2.030 & 1.203 & 2.016 & 1.604 & -0.090 \\
\hline 40 & 0.046 & 0.410 & 2.073 & 3.312 & 2.057 & 4.172 & 3.683 & 2.062 \\
\hline 50 & -0.141 & -0.089 & 0.973 & 1.243 & 3.278 & 7.449 & 7.253 & 5.773 \\
\hline 60 & -0.579 & -1.369 & -2.995 & -7.294 & 4.871 & 12.948 & 15.195 & 12.856 \\
\hline & \multicolumn{4}{|c|}{$H_{m 0}($ WES- KC92) (m) } & \multicolumn{4}{|c|}{$H_{m 0}(\mathrm{WBLM}-\mathrm{KC} 92)(\mathrm{m})$} \\
\hline 5 & -0.006 & -0.093 & -0.325 & -0.302 & -0.005 & -0.055 & -0.100 & -0.000 \\
\hline 10 & 0.019 & $-\mathbf{- 0 . 0 1 2}$ & -0.545 & -0.890 & 0.012 & -0.016 & -0.290 & -0.132 \\
\hline 20 & 0.173 & 0.141 & 0.426 & -1.206 & -0.027 & 0.013 & -0.162 & -1.308 \\
\hline 30 & 0.372 & 0.379 & 1.124 & 1.060 & -0.069 & -0.162 & -0.309 & -1.400 \\
\hline 40 & 0.498 & 0.465 & 1.032 & 2.032 & -0.099 & -0.414 & -0.448 & -2.068 \\
\hline 50 & 0.408 & 0.088 & -0.287 & -0.097 & -0.133 & -0.507 & -0.846 & -3.187 \\
\hline 60 & -0.159 & -1.343 & -4.015 & -8.514 & -0.163 & -0.555 & -0.455 & -3.374 \\
\hline
\end{tabular}



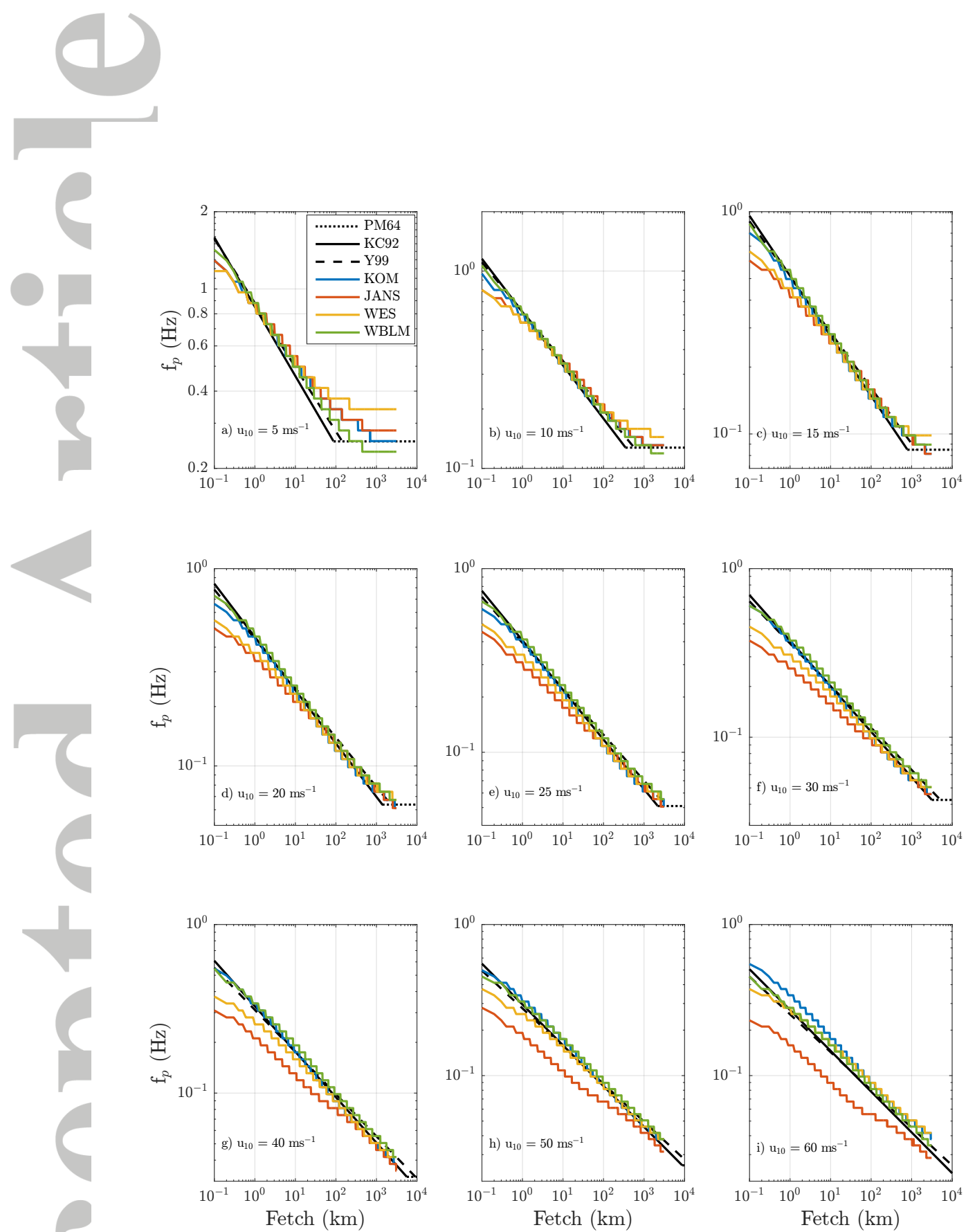

Figure 4. Peak wave frequency $f_{p}$ as a function of fetch for $10 \mathrm{~m}$ wind speed $u_{10}$ from 5 to $60 \mathrm{~ms}^{-1}$ presented in panels. The black solid and black dashed lines are from the benchmark studies of Young [1999] and Kahma and Calkoen [1992] respectively. The colored lines represent the results of the numerical experiments with wind-input source functions of KOM, JANS, WES, and WBLM respectively. 

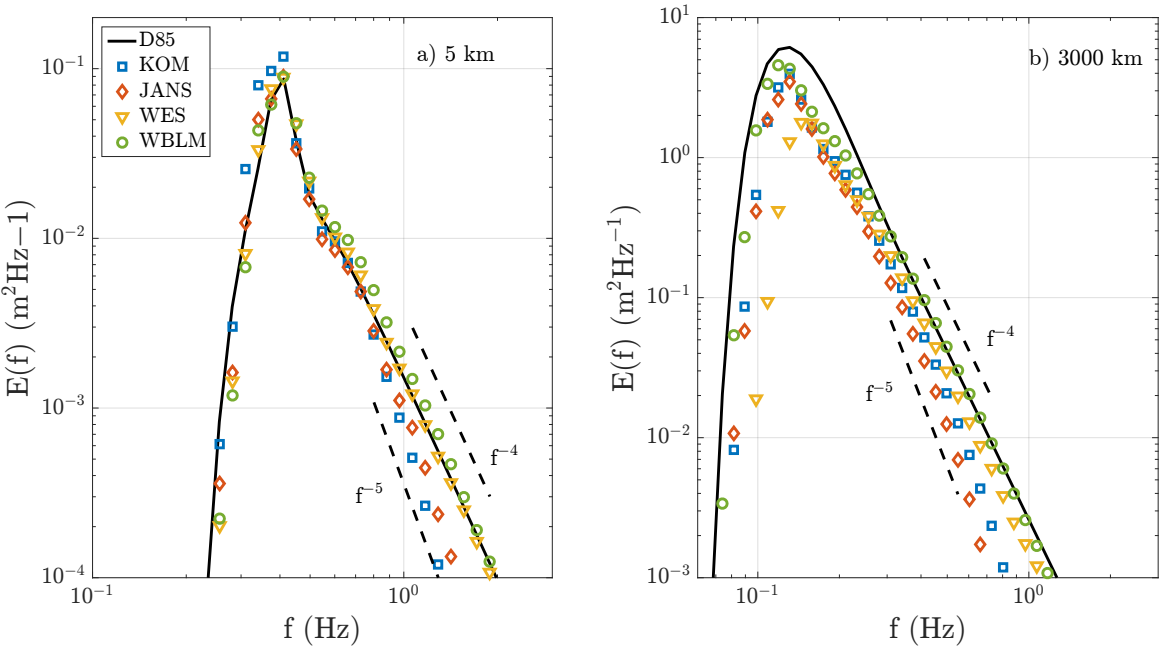

Figure 5. Direction-integrated one-dimensional wave spectra for short fetch (sub-figure a $5 \mathrm{~km}$ ) and long fetch ( sub-figure b $3000 \mathrm{~km}$ ). Both with wind speed $\left(u_{10}\right)$ of $10 \mathrm{~ms}^{-1}$. The black solid lines are calculated from Donelan et al. [1985] with $f_{p}$ estimated from Kahma and Calkoen [1992].

and again its good performance remains with different wind speeds and fetches in comparison with the original options in SWAN. Considering both the results of $H_{m 0}$ and $f_{p}$, we conclude that WBLM outperforms KOM, JANS, and WES in the idealized studies with KC92 and Y99 as references.

\subsection{Wave spectrum and source function balance}

To better understand how WBLM affects the wave growth, the wave spectrum from KOM,

JANS, WES, and WBLM are examined and presented in Figure 5, the corresponding source function balance is presented in Figures 6 and 7 for short fetch $(\mathrm{x}=5 \mathrm{~km})$ and long fetch $(\mathrm{x}$ $=3000 \mathrm{~km}$ ), respectively. Both analyses correspond to $u_{10}=10 \mathrm{~ms}^{-1}$ and $\mathrm{t}=72$ hours. It should be mentioned here that the cut-off frequency of KOM, WES, and WBLM are set to $10.5 \mathrm{~Hz}$ while JANS is set to $1.7 \mathrm{~Hz}$, without using any cap for the drag coefficient. However, if the cut-off frequency in JANS is set higher than $1.7 \mathrm{~Hz}$, the drag coefficient will be significantly overestimated and the computation will become unstable.

Figure 5 a) shows that for short fetch, the high frequency part of the wave spectrum using WES and WBLM has a $f^{-4}$ shape, which is consistent with Donelan et al. [1985] spectrum. A $f^{-4}$ tail is also seen in the experiments of Leckler et al. [2013] when they apply the breaking property based dissipation source function to WAVEWATCH III; JANS has a high 

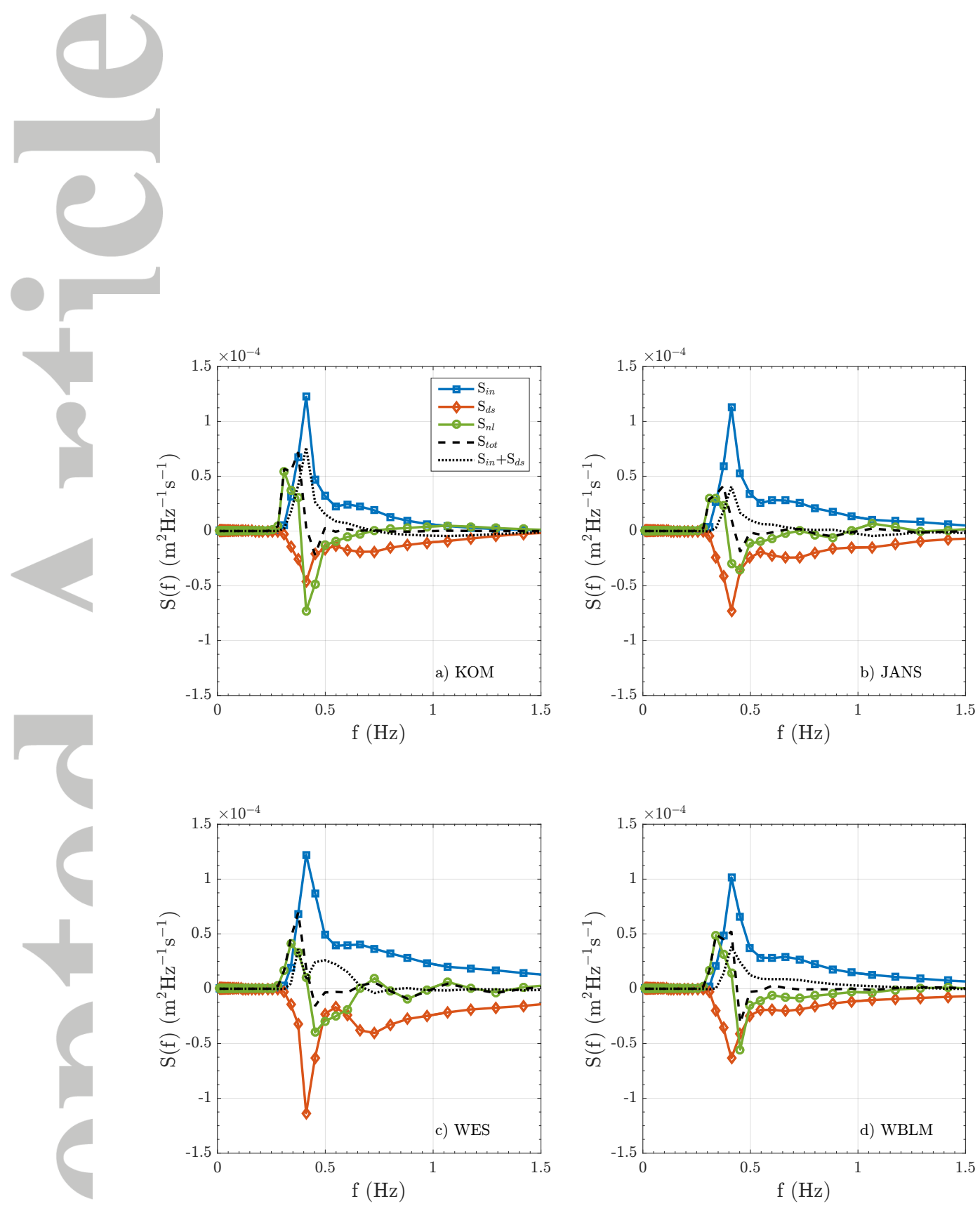

Figure 6. Direction-integrated one-dimensional source functions for short fetch $(5 \mathrm{~km})$ and wind speed $\left(u_{10}\right)$ of $10 \mathrm{~ms}^{-1}$. Sub-figure a) to d) are calculated from KOM, JANS, WES, and WBLM respectively.

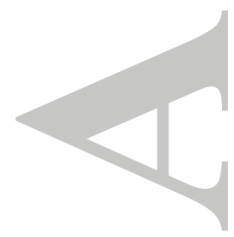



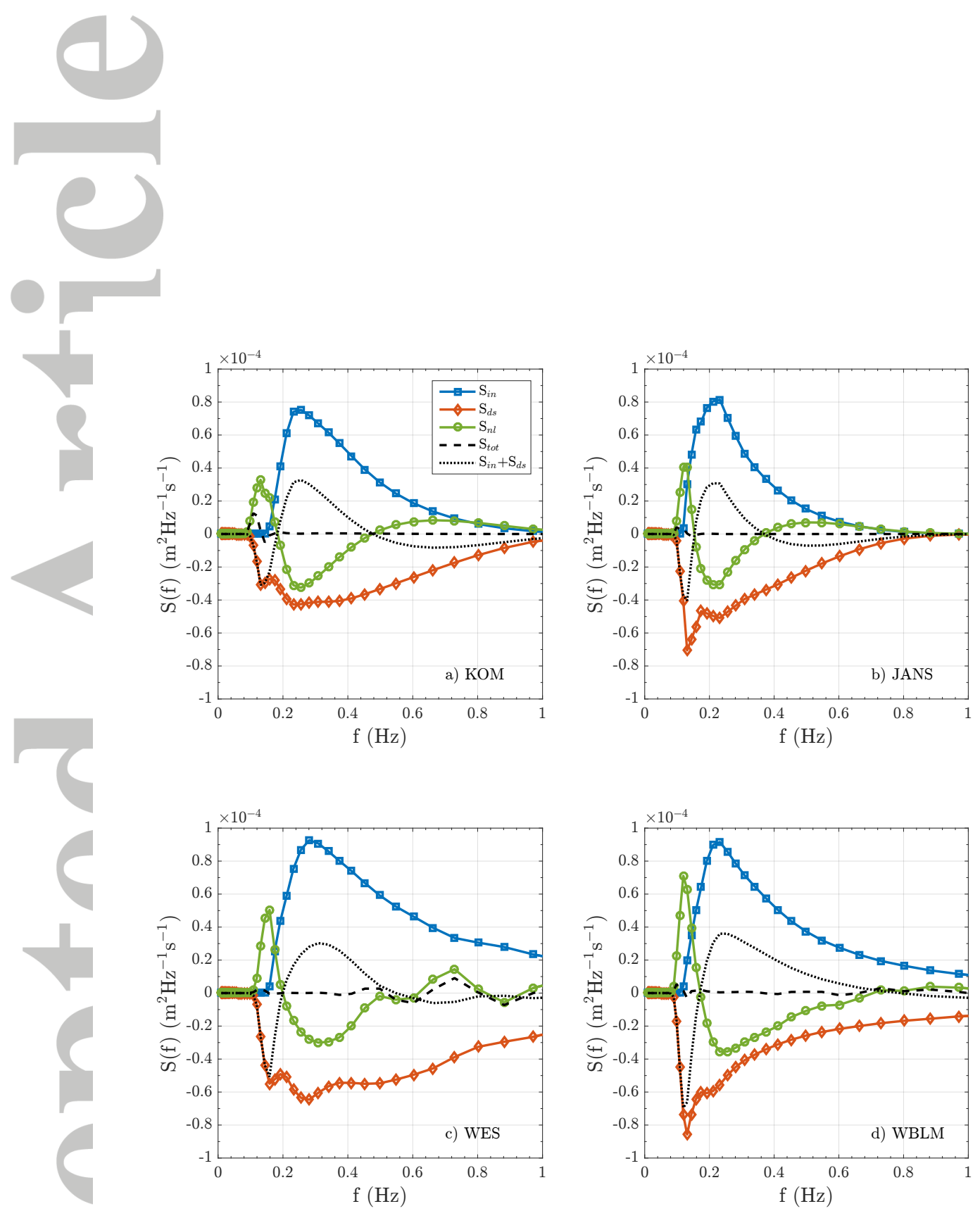

Figure 7. Direction-integrated one-dimensional source functions for long fetch (3000 km) and wind speed $\left(u_{10}\right)$ of $10 \mathrm{~ms}^{-1}$. Sub-figure a) to d) are calculated from KOM, JANS, WES, and WBLM respectively.

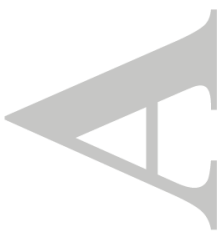


frequency spectrum shape of $f^{-5}$; KOM has a high frequency spectrum shape lower than $f^{-5}$.

Figure 6 a), b), c), and d) present the corresponding source function balance of KOM, JANS, WES, and WBLM, respectively. Near the spectral peak, $S_{\text {in }}$ of WBLM is lower than KOM, JANS, and WES; $S_{i n}$ at the high frequency part are closely related to the spectral tail level. Thus, $S_{i n}$ of WES at high frequencies are much larger than that of KOM because the spectral tail level of WES is $f^{-4}$ while that of KOM is lower than $f^{-5}$. Similarly, although $S_{i n}$ of KOM around $f_{p}$ are much larger than that of WBLM, $S_{i n}$ of WBLM at the high frequency part are larger than KOM because the former has a tail level of $f^{-4}$ while the latter has one lower than $f^{-5}$.

Figure $5 \mathrm{~b})$ presents the one-dimensional wave spectrum at long fetch $(\mathrm{x}=3000 \mathrm{~km})$ where $f_{p}$ reaches Pierson-Moskowitz limit. For this case, WES and WBLM maintain a spectral tail level of $f^{-4}$; KOM and JANS maintain a spectral tail level of $f^{-5}$ or lower. The corresponding source functions are shown in Figure 7. $S_{t o t}$ in the four panels are close to zero, which means that the waves are fully developed. The spectral shape of WBLM $S_{i n}$ is similar to WES. Both of them have higher wind-input than KOM and JANS in high frequencies.

From the results of Figures 5, 6 and 7, we conclude that the new pair of WBLM $S_{i n}$ and $S_{d s}$ succeeded in reproducing Donelan et al. [1985] wave spectrum under idealized fetchlimited condition and maintains a $f^{-4}$ high frequency tail.

\subsection{Stress balance and wind profile}

In Section 3.1, we described the momentum conservation within the WBL (equation 15). The wave-induced stress is integrated from $S_{i n}$ following equation (9). Figure 8 shows the stress distribution and the wind profile within the WBL for $u_{10}=10 \mathrm{~ms}^{-1}$ (Figure $8 \mathrm{a}, \mathrm{b}$ ), and $u_{10}$ $=40 \mathrm{~ms}^{-1}$ (Figure $8 \mathrm{c}, \mathrm{d}$ ) after 72 hours, respectively. The vertical distribution of $\vec{\tau}_{t}, \vec{\tau}_{w}$, and $\vec{\tau}_{t o t}$ show similar features as Makin and Mastenbroek [1996] (Figure 1 in their paper). The viscous sublayer height and WBL height are marked as black squares and black circles, respectively. Within the viscous sublayer, $\vec{\tau}_{t}$ remains constant; above WBL, $\vec{\tau}_{t}=\vec{\tau}_{t o t} . \vec{\tau}_{t o t}=\vec{\tau}_{w}+$ $\vec{\tau}_{t}$ remains constant with height throughout WBL. The viscous sublayer height and WBL height at $u_{10}=40 \mathrm{~ms}^{-1}$ are higher than those at $u_{10}=10 \mathrm{~ms}^{-1}$. The blue solid lines in Figure $8 \mathrm{~b})$ and d) are the wind profiles in the lower $10 \mathrm{~m}$ of the atmospheric boundary layer. It shows the same feature as Moon et al. [2004] (Figure 9 in their paper), that within the WBL, the wind profiles are not logarithmic. Since $z_{0}$ is a parameter that is usually used in the atmospheric 

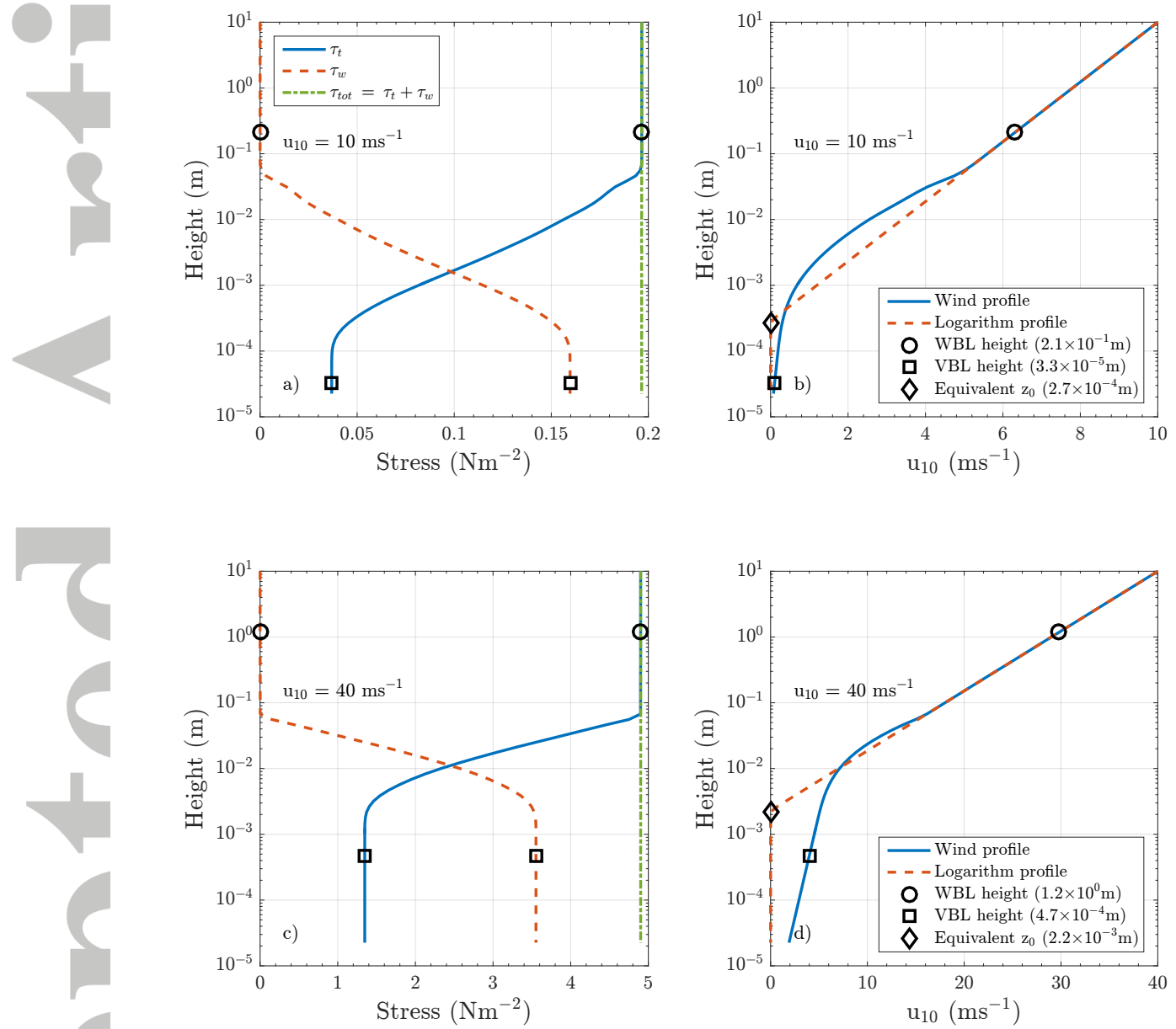

Figure 8. Vertical distribution of stress and wind profile after 72 hours simulation at $3000 \mathrm{~km}$ fetch.

Sub-figure a) and b) are in $10 \mathrm{~ms}^{-1}$ wind speed condition; sub-figure c) and d) are in $40 \mathrm{~ms}^{-1}$ wind speed condition; sub-figure a) and c) present wave-induced stress $\vec{\tau}_{w}$, turbulent stress $\vec{\tau}_{t}$, and total stress $\vec{\tau}_{t o t}=\vec{\tau}_{t}+$ $\vec{\tau}_{w}$ vary with height; sub-figure b) and d) present the corresponding wind profiles. The WBL height, viscus sub-layer (VBL) height, and equivalent $z_{0}$ are mark as circles, squares, and diamonds, respectively. 
models, an equivalent $z_{0}$ (marked by black diamonds) could be obtained by extending the logarithmic wind profile from higher levels into WBL (red dashed lines).

\subsection{Drag coefficient}

The dependence of $C_{d}$ on $u_{10}$, fetch $x$ and simulating time t are displayed in Figure 9.

Figure 9 a) and b) present the $C_{d}-u_{10}$ relationships simulated in this study with JANS and

WBLM $S_{i n}$, respectively, including field measurements compiled by Soloviev et al. [2014], drag relations from $W u$ [1982], Zijlema et al. [2012], and COARE3.0 [Fairall et al., 2003]. The red solid line with triangles in Figure 9 a) shows the mean $C_{d}$ calculated from JANS for each wind speed. It is clear that JANS significantly overestimates $C_{d}$ when compared with measurements. The overestimation grows with increasing wind speed. $W u$ [1982] and COARE3.0 approximately follow the upper bound of the measurement data for $u_{10}<30 \mathrm{~ms}^{-1}$, but continues to increase at stronger winds. Zijlema et al. [2012] approximately follows the trend of the measurement data, because it is fitted from the similar dataset. However, it has no wave parameterization and cannot explain the variance of the measurement data for each wind speed. The green solid line with inverted triangles in Figure 9 b) shows the mean $C_{d}$ calculated from WBLM for each wind speed. $C_{d}$ of WBLM follows the trend of the measurement data and its distribution gives a wide overlapping with the measurement data for $u_{10} \leq 40 \mathrm{~ms}^{-1}$, though the variance of $C_{d}$ at each wind speed is still small compared with measurements. Considering that the waves are much more complex in the ocean compared with the idealized fetch-limited experiments, the variance of $C_{d}$ calculated by WBLM is expected to be larger in real applications. For $u_{10}>40 \mathrm{~ms}^{-1}, C_{d}$ from WBLM does not decrease with $u_{10}$. The decrease of $C_{d}$ with $u_{10}$ has been attributed to different processes such as sea spray [e.g. Chen and Yu, 2016], which needs further investigations.

Figure 9 c) and d) present the variation of $C_{d}$ with fetch and simulation time, calculated from WBLM for four wind speeds, respectively. The fetch and duration dependence of $C_{d}$ calculated from WBLM in this study show similar tendency as the Hwang [2005] model. Compared with the Hwang [2005] model, $C_{d}$ of WBLM has lower values, and peaks at longer fetch and longer time. For fetches shorter than $10 \mathrm{~km}, C_{d}$ increases with fetch; for fetches longer than $10 \mathrm{~km}, C_{d}$ decreases with fetch. $C_{d}$ increases with time in the first 1 or 2 hours and decreases with time afterwards. 

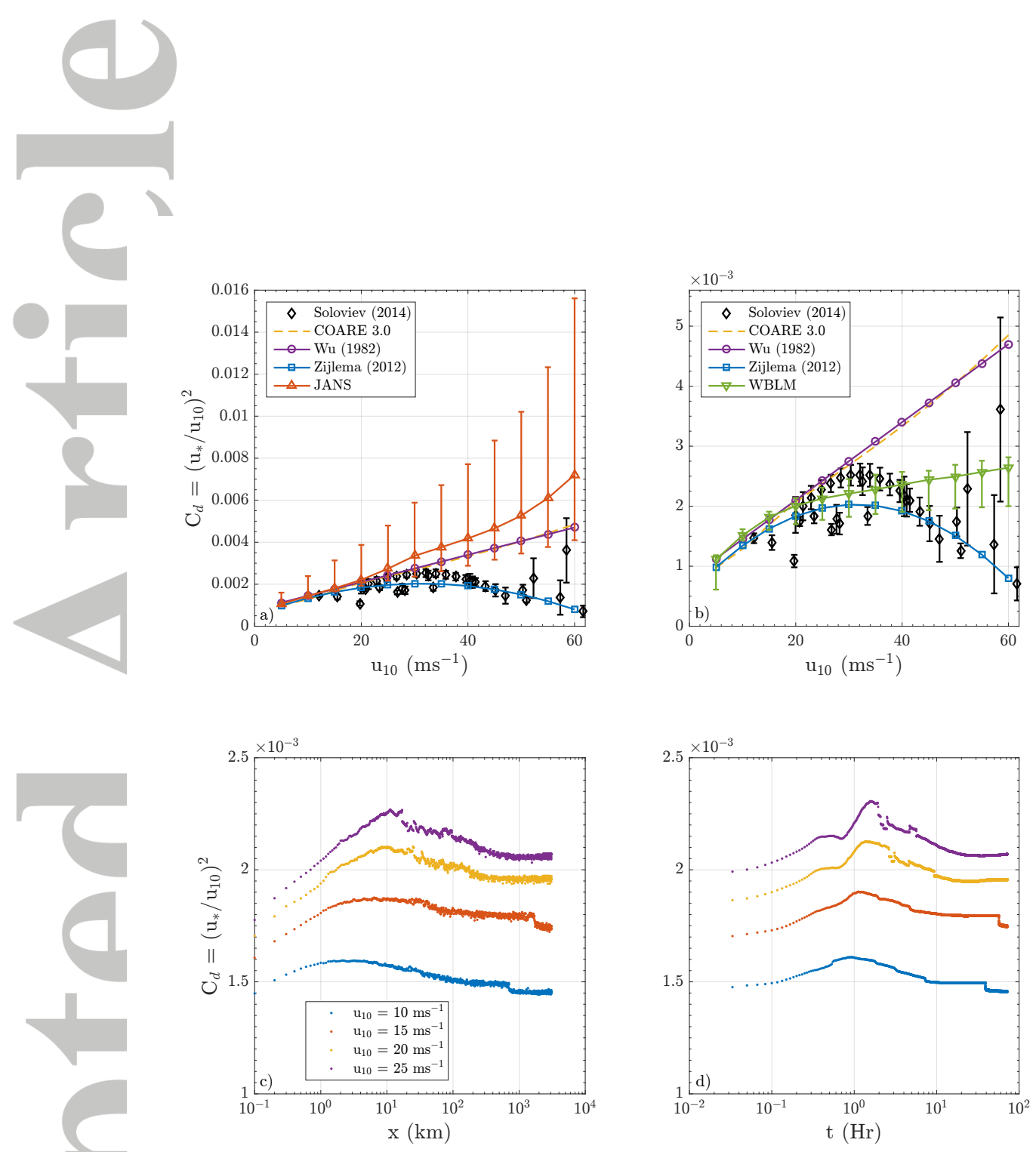

Figure 9. Drag coefficient $\left(C_{d}\right)$ as a function of $u_{10}(\mathrm{a}, \mathrm{b})$, fetch (c), and simulating time (d). Sub-figure a) and b) present the distribution of $C_{d}$ modeled by JANS (red triangle with bars) and WBLM (green inverted triangle with bars) after 72 hours at all fetches, respectively. The black diamonds with error bars in sub-figure a) and b) are from field measurements compiled by Soloviev et al. [2014]. The orange dashed lines are from COARE3.0 [Fairall et al., 2003]. The purple solid lines with circles and blue solid lines with squares are from KOM $S_{i n}\left[W u, 1982\right.$; Zijlema et al., 2012]. Sub-figure c) and d) present $C_{d}$ as a function of fetch after 72 hours and $C_{d}$ as a function of simulating time at $3000 \mathrm{~km}$ calculated from WBLM. 


\section{Discussion}

In previous wave studies [e.g. Moon et al., 2004, 2009; Chen and Yu, 2016], the wave boundary layer model was used in the estimation of $C_{d}$, but not used directly in the calculation of $S_{i n}$ in the wave model. Reichl et al. [2014] reported that $C_{d}$ is very sensitive to the energy, level at the spectral tail and the calculation methods. From equations (16) to (18), it

is also clear that the estimated $C_{d}$ is highly dependent on the shape of the wave spectrum and the Miles constant, $C_{\beta}$, in equation (18). At the same time, $S_{i n}$ of the wave model is highly dependent on the magnitude of $C_{d}$. Thus, there will be uncertainties if the growth rate $\beta_{g}$ for $S_{i n}$ of the wave model is different from the one used for the estimation of $C_{d}$ as in many previous studies. In this study, the same $\beta_{g}$ is used for the calculation of $S_{i n}$ and $C_{d}$ with the WBLM.

The choice of the Miles constant, $C_{\beta}$, affects the magnitude of $S_{i n}$ and $C_{d}$ through increasing or decreasing $\beta_{g}$. In Hara and Belcher [2002], $C_{\beta}=40$; in Moon et al. [2004], $C_{\beta}$ = 32; in Reichl et al. [2014] and Chen and $Y u$ [2016], $C_{\beta}=25$. In this study, we use equation (6) according to Janssen [1991], with the constant $J=1.6$ according to Banner and Morison [2010]. The non-dimensional growth rates, $\beta_{g} / f$, as a function of $u_{*}^{l} / c$ calculated from JANS and WBLM are shown in Figure 10. For comparison, the observations as compiled by [Plant, 1982] are also plotted. Both JANS and WBLM show fair agreement with observations. The dissipation source function indirectly affects the magnitude of $S_{i n}$ and $C_{d}$ by influencing the wave spectrum and the energy level in high frequency tail. Although there have been more physically based dissipation source functions developed in recent years in the literature [e.g. Ardhuin et al., 2010; Banner and Morison, 2010; Leckler et al., 2013], in this study, we mainly concern the wind-input source function. Thus, we only re-calibrated the dissipation coefficients of Komen et al. [1984] instead of implementing a new dissipation source function in SWAN. A more physically based dissipation source function could be considered in a future study.

WBLM is sensitive to the choice of the cut-off frequency for wind speed less than 10 $\mathrm{ms}^{-1}$ and for short fetches. Sensitivity experiments show that reducing the cut-off frequency from $10.5 \mathrm{~Hz}$ to $1 \mathrm{~Hz}$ do not have significant impact on the calculation of wave growth for wind speed higher than $10 \mathrm{~ms}^{-1}$. However, at wind speed of $5 \mathrm{~ms}^{-1}$, the wave growth is considerably reduced when the $1 \mathrm{~Hz}$ cut-off frequency is used, since it is close to the peak frequency. 

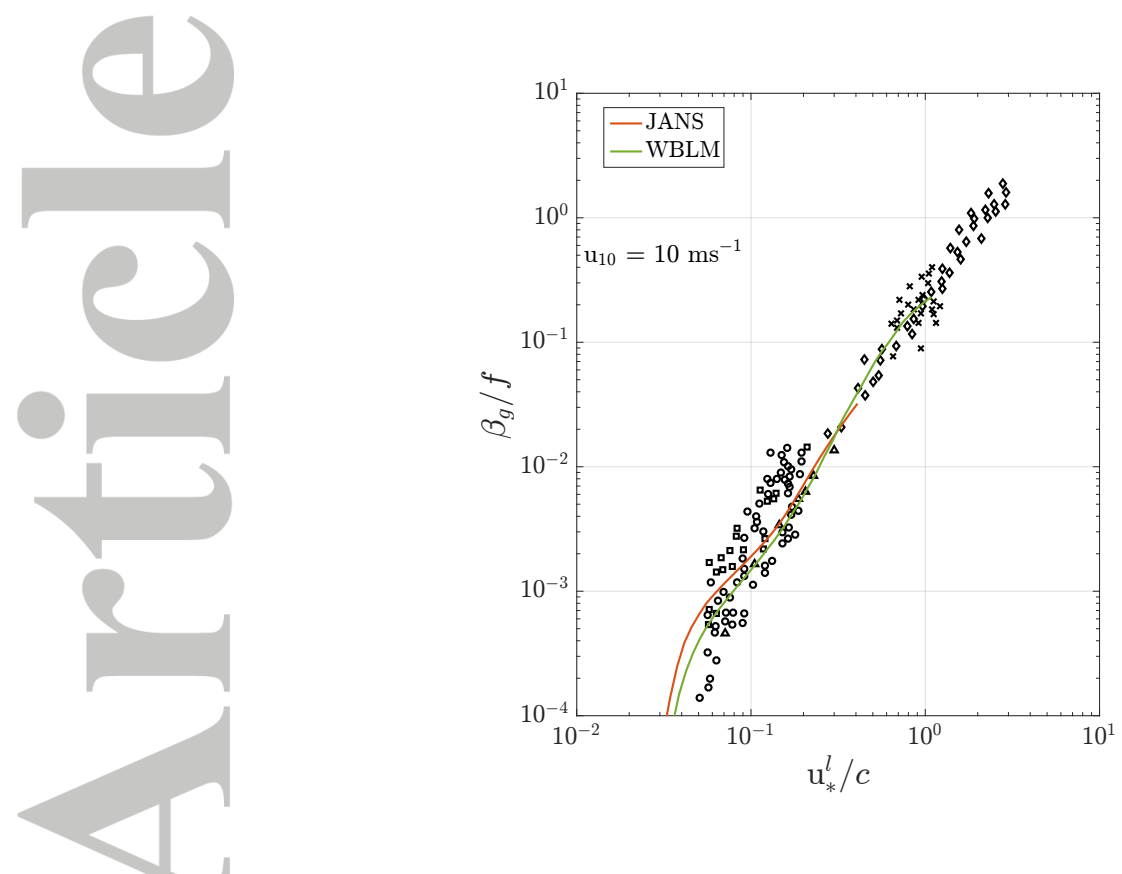

Figure 10. Dimensionless growth rate $\beta_{g} / f$ as a function of $u_{*}^{l} / c$ calculated in SWAN using JANS and WBLM respectively for $u_{10}=10 \mathrm{~ms}^{-1}, \mathrm{x}=3000 \mathrm{~km}$ after 72 hours. Black marks are observations compiled by [Plant, 1982].

\section{Conclusions}

In this study, a modification of Janssen [1991] wind-input source function was done by introducing a wave boundary layer model (WBLM) [Moon et al., 2004] to SWAN. The WBLM is based on the momentum and kinetic energy conservation at the air sea interface. The spectral sheltering mechanism is implicitly taken into account. Accordingly, the dissipation parameters due to white capping are re-calibrated by introducing a ratio factor, $R_{d s}=S_{i n} / S_{d s}$.

A new way of parameterizing $R_{d s}$ is developed so that the $H_{m 0}$-fetch relations agree with benchmark studies and the wave spectrum maintains a $f^{-4}$ high frequency tail. The WBLM is validated through numerical fetch-limited wave evolution experiments. Results of $H_{m 0}$-fetch and $f_{p}$-fetch relations are compared with benchmark studies [Kahma and Calkoen, 1992; Young, 1999] and numerical results of the other three original $S_{i n}$ in SWAN [Komen et al., 1984; Janssen, 1991; van der Westhuysen et al., 2007]. Results show that the growth curves simulated using WBLM are in good agreement with the benchmark studies. The quality of the growth curves with WBLM are independent of wind speed and fetch, and they are closer to the benchmark curves than with the other three original $S_{i n}$ in SWAN (Figure 3 and 4). It indicates that the WBLM could be applied to a wider range of wind speed and sea state conditions than the original ones in SWAN. 

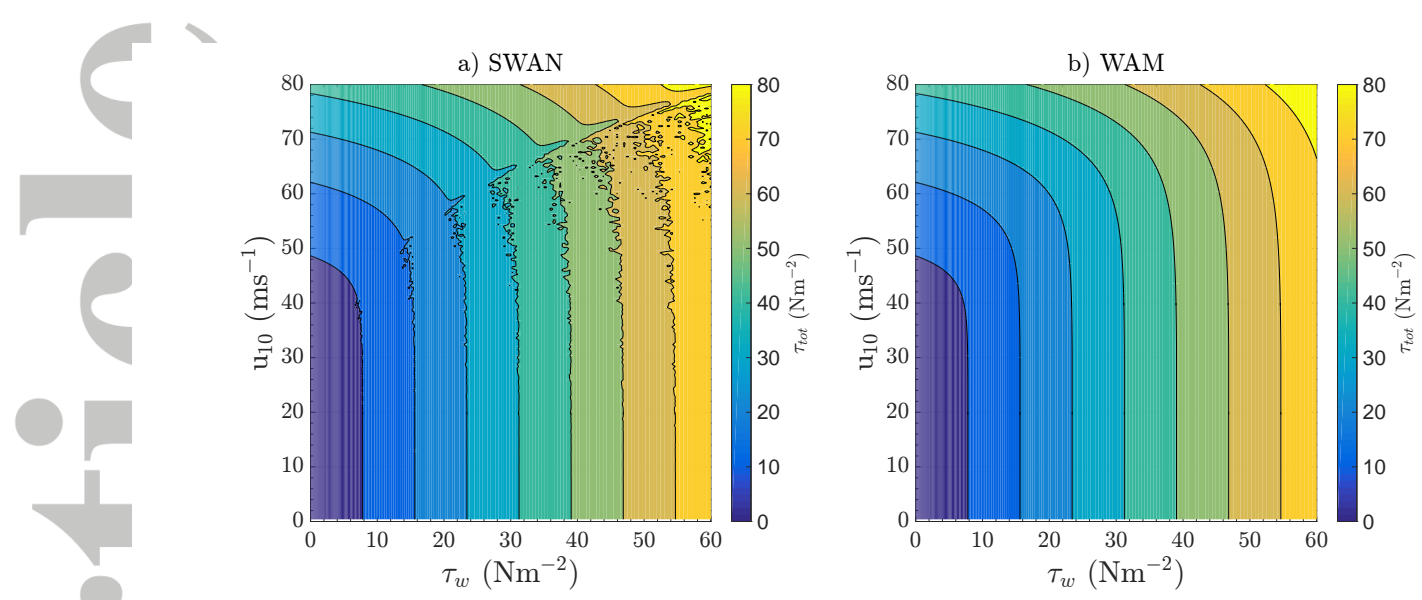

Figure A.1. Stress table [Janssen, 1991] used in SWAN (sub-figure a) and WAM (sub-figure b).

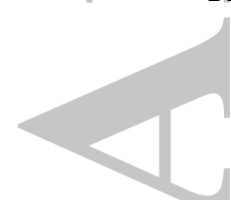

The WBLM explicitly calculates the momentum budget within the air-sea interface. The simulated drag coefficients from the experiments are compared with both field and laboratory measurements as compiled by Soloviev et al. [2014]. Results show that the WBLM provides reliable drag coefficient estimation as well as wave estimation for fetch limited conditions under a wide range of wind speed. The results also reflect the fact that the variation of measured drag coefficients at a certain wind speed are related to the state of the underlying waves. Be-

sides the drag-wind speed dependence, clear drag-fetch and drag-duration dependences are also found. For short fetch $(\mathrm{x} \leq 10 \mathrm{~km})$, drag coefficient increases with fetch; for longer fetch (x $>10 \mathrm{~km})$, drag coefficient decreases with fetch. In the first 1 or 2 hours, drag coefficient increases with time, after that, it decreases with time.

The approach of applying WBLM in $S_{i n}$ can also be used in other ocean wave models. The drag coefficient or equivalent roughness length calculated in the WBLM can be further used in wind-wave coupling model systems to improve the momentum flux estimation between wave and atmospheric models.

\section{A: Stress table in SWAN}

The drag relations according to the stress table of Janssen [1991] (from equation 7 to equation 10) calculated by SWAN numerical algorithm and WAM (https://github.com/mywave/WAM) numerical algorithm are compared in Figure A.1. Both are calculated outside SWAN with given wind speed ranges from 0 to $80 \mathrm{~ms}^{-1}$ and $\vec{\tau}_{w}$ ranges from 0 to $60 \mathrm{Nm}^{-2}$. By comparing subfigures A.1 a) and b) it is noticed that the algorithm in SWAN causes numerical noise when 
the relation of $u_{10}$ and $\vec{\tau}_{w}$ reaches certain threshold. In this study, this is avoided by replacing the SWAN algorithm with WAM.

\section{B: Derivation of dissipation coefficient}

The dissipation ratio $R_{d s}$ as described in equation (25) is parameterized as a function of inverse wave age $u_{10} / c_{p}$ in Babanin et al. [2010]. However, this parameterization cannot reproduce the benchmark fetch-limited curves of KC92 [Kahma and Calkoen, 1992] and Y99 [Young, 1999] with WBLM in SWAN. Therefore, in this study, we developed a new method to parameterize $R_{d s}$ as follows.

First we do the simulation using WBLM with constant $R_{d s}=0.85$. As shown in Figure B.1 a), dimensionless energy-fetch curves (hereafter curves) are close to the benchmark study of KC92 for wind speed from 5 to $60 \mathrm{~ms}^{-1}$. It is very clear that the curves depend on the wind speed. Similar wind speed dependence is also found using JANS and KOM (sub-figure

d). We found that such wind speed dependency could be removed by introducing a normalized wind speed:

$$
\widetilde{E}^{\prime}=\widetilde{E}\left(\frac{10 m s^{-1}}{u_{10}}\right)^{\frac{1}{2}}
$$

The curves after introducing $\left(\frac{10}{u_{10}}\right)^{\frac{1}{2}}$ (hereafter the unit of $10 \mathrm{~ms}^{-1}$ are removed) are shown in Figure B.1 b). For $\widetilde{E}>1.4 \times 10^{-5}$, the curves are close to KC92. But for $\widetilde{E} \leq 1.4 \times$ $10^{-5}$, the curves are lower than KC92. The curves for $\widetilde{E} \leq 1.4 \times 10^{-5}$ can be fitted by equation (29) with $A_{e}=2.217 \times 10^{-7}$ and $B_{e}=1.125$, which is shown in Figure B.1 b) as the black dashed line. Thus, the expected equation of $R_{d s}$ should contain two main terms: $\left(\frac{10}{u_{10}}\right)^{\frac{1}{2}}$ and $\widetilde{E}$.

By integrating equation (1) over $\sigma$ and $\theta\left(\sum S_{n l}=0\right)$, in duration-unlimited condition $\left(\frac{\partial}{\partial t}=0\right)$, the action balance equation can be written as:

$$
\frac{\partial E}{\partial x}=\sum S_{i n}-\sum S_{d s}=\left(1-R_{d s}\right) \sum S_{i n}
$$

For $R_{d s}=0.85$ :

$$
\frac{\partial E_{0}}{\partial x}=0.15 \sum S_{i n}
$$

Considering Figure B.1 a) and b), the equation of the curves can be written as:

$$
\widetilde{E_{0}}\left(\frac{10}{u_{10}}\right)^{\frac{1}{2}}=A_{0} \widetilde{x}^{B_{0}}
$$

Assuming that we can find a $R_{d s}$ that reproduces KC92 curve:

$$
\widetilde{E_{k}}=A_{k} \widetilde{x}^{B_{k}}
$$



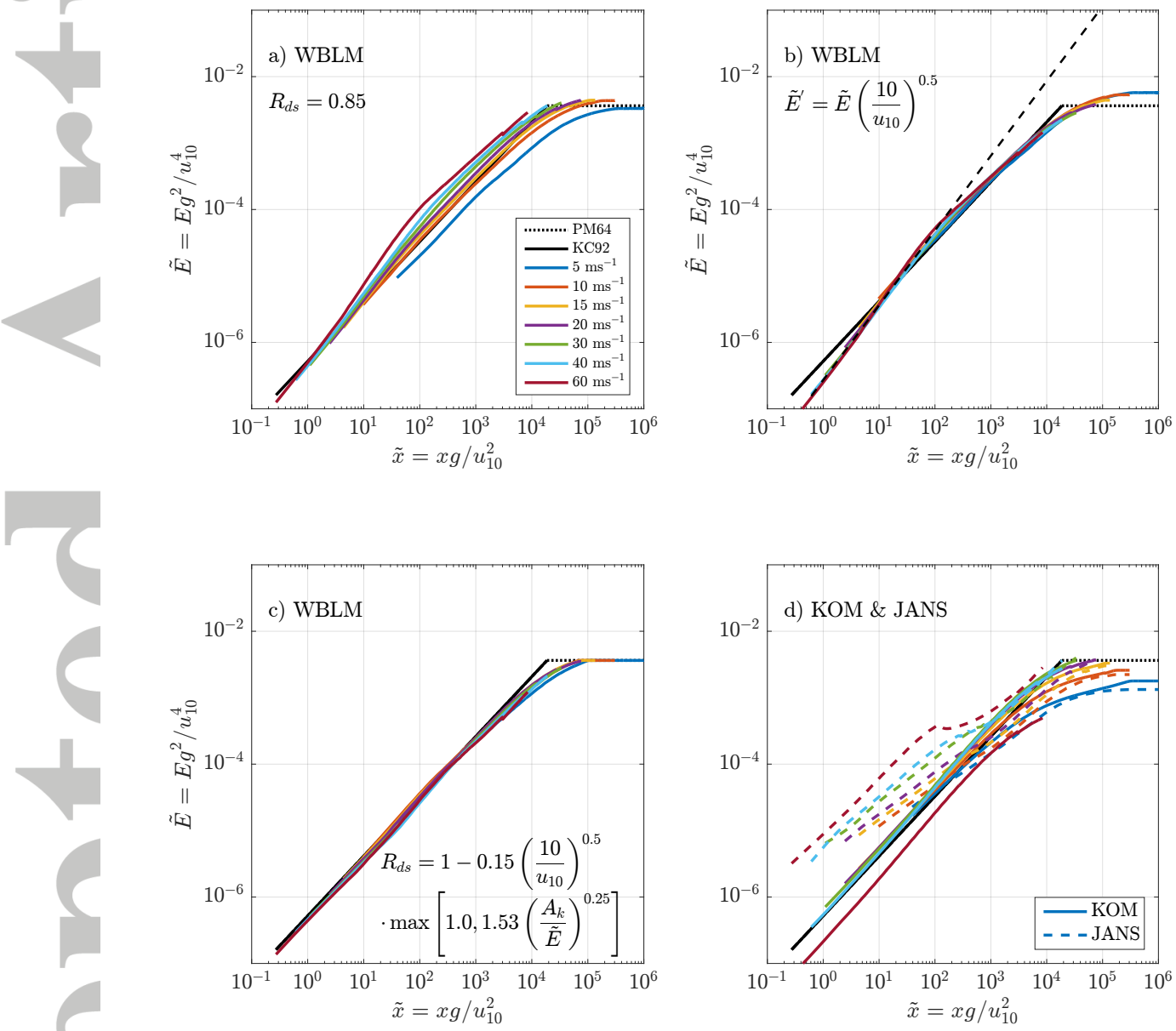

Figure B.1. Non-dimensional energy $\widetilde{E}=E g^{2} / u_{10}^{4}$ as a function of non-dimensional fetch $\widetilde{x}=x g / u_{10}^{2}$.

The black solid lines are from the benchmark study of Kahma and Calkoen [1992]. The colored lines describe the results of different numerical experiments; sub-figure a), b) and c) show the results of WBLM with different $R_{d s}$; sub-figure d) shows the results of JANS (dashed lines) and KOM (solid lines). 
where the values of $A_{k}$ and $B_{k}$ are from KC92. The combination of equations (B.2) and (B.3)

will result in the equation for $R_{d s}$ :

$$
R_{d s}=1-0.15 \frac{\partial E_{k}}{\partial E_{0}}
$$

From equations (B.4) and (B.5), we can find the solution for equation (B.6):

$$
R_{d s}=1-0.15\left(\frac{10}{u_{10}}\right)^{\frac{1}{2}} \frac{B_{k} \widetilde{E_{k}}}{A_{0} B_{0}}\left(\frac{\widetilde{E_{k}}}{A_{k}}\right)^{-\frac{B_{0}}{B_{k}}}
$$

For $\widetilde{E} \leq 1.4 \times 10^{-5}, A_{0}=2.217 \times 10^{-7}, B_{0}=1.125 ; A_{k}=5.2 \times 10^{-7}, B_{k}=0.9$. So equation (B.7) becomes:

$$
R_{d s}=1-0.15\left(\frac{10}{u_{10}}\right)^{\frac{1}{2}} \cdot 1.53\left(\frac{5.2 \times 10^{-7}}{\widetilde{E}}\right)^{\frac{1}{4}}
$$

And for $\widetilde{E}>1.4 \times 10^{-5}, A_{0}=A_{k}=5.2 \times 10^{-7}, B_{0}=B_{k}=0.9$, thus equation (B.7) becomes:

$$
R_{d s}=1-0.15\left(\frac{10}{u_{10}}\right)^{\frac{1}{2}}
$$

Here we introduce a maximum function so that equation (B.8) transfers to equation (B.9) smoothly:

$$
R_{d s}=1-0.15\left(\frac{10}{u_{10}}\right)^{\frac{1}{2}} \cdot \max \left[1.0,1.53\left(\frac{5.2 \times 10^{-7}}{\widetilde{E}}\right)^{\frac{1}{4}}\right]
$$

For $\widetilde{E}>3.64 \times 10^{-3}, R_{d s}=1$; the value $3.64 \times 10^{-3}$ is the Pierson-Moskowitz limit [Pier-

son and Moskowitz, 1964]. Results using the new $R_{d s}$ equation at wind speed ranges from 5

to $60 \mathrm{~ms}^{-1}$ are shown together in Figure B.1 c). It is clearly seen that with the new $R_{d s}$ equation, the result of dimensionless energy-fetch relation is significantly improved.

\section{Acronyms}

JANS Wind-input source function according to Janssen [1991].

KOM Wind-input source function according to Komen et al. [1984].

WES Wind-input source function according to van der Westhuysen et al. [2007].

WBL Wave boundary layer.

WBLM Wind-input source function of Janssen [1991] refined by WBL model.

PM64 Pierson-Moskowitz limit [Pierson and Moskowitz, 1964].

KC92 Fetch-limited wave evolution according to Kahma and Calkoen [1992].

Y99 Fetch-limited wave evolution according to Young [1999].

DIA Discrete Interaction Approximation method [Hasselmann and Hasselmann, 1985] for nonlinear four wave interaction. 
XNL Exact method [van Vledder, 2006] for non-linear four wave interaction.

\section{Acknowledgments}

This study is funded by the Danish Forskel project X-WiWa (PSO-12020). We are grateful to Mark C. Kelly, Søren Ejiling Larsen, Ebba Dellwik at DTU Wind Energy, and Henrik Kofoed-

Hansen from DHI for helpful discussions and inputs. Furthermore, we would like to thank Nikhil Garg from Nanyang Technological University for his helpful suggestions. The source code for SWAN used in this study is freely available at http://swanmodel.sourceforge.net. All data for this paper is properly cited and referred to in the reference list.

\section{References}

Alves, J. H. G. M., and M. L. Banner (2003), Performance of a SaturationBased Dissipation-Rate Source Term in Modeling the Fetch-Limited Evolution of Wind Waves, Journal of Physical Oceanography, 33(6), 1274-1298, doi:10.1175/1520-0485(2003)033<1274:POASDS >2.0.CO;2.

Ardhuin, F., E. Rogers, A. V. Babanin, J.-F. Filipot, R. Magne, A. Roland, A. van der Westhuysen, P. Queffeulou, J.-M. Lefevre, L. Aouf, and F. Collard (2010), Semiempirical Dissipation Source Functions for Ocean Waves. Part I: Definition, Calibration, and Validation, Journal of Physical Oceanography, 40(9), 1917-1941, doi:10.1175/2010JPO4324.1.

Babanin, A. V., K. N. Tsagareli, I. R. Young, and D. J. Walker (2010), Numerical Investigation of Spectral Evolution of Wind Waves. Part II: Dissipation Term and Evolution Tests, Journal of Physical Oceanography, 40(4), 667-683, doi:10.1175/2009JPO4370.1.

Banner, M. L., and R. P. Morison (2010), Refined source terms in wind wave models with explicit wave breaking prediction. Part I: Model framework and validation against field data, Ocean Modelling, 33(1-2), 177-189, doi:10.1016/j.ocemod.2010.01.002.

Banner, M. L., A. V. Babanin, and I. R. Young (2000), Breaking Probability for Dominant Waves on the Sea Surface, Journal of Physical Oceanography, 30(12), 3145-3160, doi:10.1175/1520-0485(2000)030<3145:BPFDWO>2.0.CO;2.

Booij, N., R. C. Ris, and L. H. Holthuijsen (1999), A third-generation wave model for coastal regions: 1. Model description and validation, Journal of Geophysical Research: Oceans, 104(C4), 7649-7666, doi:10.1029/98JC02622. 
Bottema, M., and G. P. van Vledder (2009), A ten-year data set for fetchand depth-limited wave growth, Coastal Engineering, 56(7), 703-725, doi:10.1016/j.coastaleng.2009.01.012.

Cavaleri, L., J. H. G. M. Alves, F. Ardhuin, A. Babanin, M. Banner, K. Belibassakis, M. Benoit, M. Donelan, J. Groeneweg, T. H. C. Herbers, P. Hwang, P. A. E. M. Janssen, T. Janssen, I. V. Lavrenov, R. Magne, J. Monbaliu, M. Onorato, V. Polnikov, D. Resio, W. E. Rogers, A. Sheremet, J. McKee Smith, H. L. Tolman, G. van Vledder, J. Wolf, and I. Young (2007), Wave modelling - The state of the art, Progress in Oceanography, 75(4), 603-674, doi:10.1016/j.pocean.2007.05.005.

Chalikov, D. V., and V. K. Makin (1991), Models of the wave boundary layer, BoundaryLayer Meteorology, 56(1-2), 83-99, doi:10.1007/BF00035383.

Charnock, H. (1958), A note on empirical wind-wave formulae, Quarterly Journal of the Royal Meteorological Society, 84(362), 443-447.

Chen, G., and S. E. Belcher (2000), Effects of Long Waves on WindGenerated Waves, Journal of Physical Oceanography, 30(9), 2246-2256, doi:10.1175/1520-0485(2000)030<2246:EOLWOW>2.0.CO;2.

Chen, Y., and X. Yu (2016), Enhancement of wind stress evaluation method under storm conditions, Climate Dynamics, 1-11, doi:10.1007/s00382-016-3044-4.

Donelan, M. A., J. Hamilton, and W. H. Hui (1985), Directional Spectra of WindGenerated Waves, Philosophical Transactions of the Royal Society A: Mathematical, Physical and Engineering Sciences, 315(1534), 509-562, doi:10.1098/rsta.1985.0054. Edson, J. B., V. Jampana, R. A. Weller, S. P. Bigorre, A. J. Plueddemann, C. W. Fairall, S. D. Miller, L. Mahrt, D. Vickers, and H. Hersbach (2013), On the Exchange of Momentum over the Open Ocean, Journal of Physical Oceanography, 43(8), 1589-1610, doi:10.1175/JPO-D-12-0173.1.

Fairall, C. W., E. F. Bradley, J. E. Hare, A. A. Grachev, and J. B. Edson (2003), Bulk parameterization of air-sea fluxes: Updates and verification for the COARE algorithm, Journal of Climate, 16(4), 571-591, doi:10.1175/1520-0442(2003)016<0571:BPOASF >2.0.CO;2.

Filipot, J. F., and F. Ardhuin (2012), A unified spectral parameterization for wave breaking: From the deep ocean to the surf zone, Journal of Geophysical Research: Oceans, 117(4), 1-19, doi:10.1029/2011JC007784. 
Gagnaire-Renou, E., M. Benoit, and S. I. Badulin (2011), On weakly turbulent scaling of wind sea in simulations of fetch-limited growth, Journal of Fluid Mechanics, 669, 178-213, doi:10.1017/S0022112010004921.

Hara, T., and S. E. Belcher (2002), Wind forcing in the equilibrium range of wind-wave spectra, Journal of Fluid Mechanics, 470, 223-245, doi:10.1017/S0022112002001945.

Hara, T., and S. E. Belcher (2004), Wind profile and drag coefficient over mature ocean surface wave spectra, Journal of Physical Oceanography, 34(11), 2345-2358, doi:10.1175/JPO2633.1.

Hasselmann, K., T. P. Barnett, E. Bouws, H. Carlson, D. E. Cartwright, K. Enke, J. A. Ewing, H. Gienapp, D. E. Hasselmann, P. Kruseman, A. Meerburg, P. Muller, D. J. Olbers, K. Richter, W. Sell, and H. Walden (1973), Measurements of Wind-Wave Growth and Swell Decay during the Joint North Sea Wave Project (JONSWAP), Ergnzungsheft zur Deutschen Hydrographischen Zeitschrift Reihe, A(8)(12), p.95, doi:citeulike-article-id:2710264.

Hasselmann, S., and K. Hasselmann (1985), Computations and Parameterizations of the Nonlinear Energy Transfer in a Gravity-Wave Spectrum. Part I: A New Method for Efficient Computations of the Exact Nonlinear Transfer Integral, Journal of Physical Oceanography, 15(11), 1369-1377, doi:10.1175/1520-0485(1985)015<1369:CAPOTN>2.0.CO;2.

Hersbach, H., and P. A. E. M. Janssen (1999), Improvement of the short-fetch behavior in the Wave Ocean Model (WAM), Journal of Atmospheric and Oceanic Technology, 16(7), 884-892, doi:10.1175/1520-0426(2001)018<0711:COIOTS $>2.0$. CO;2.

Huang, Y., R. H. Weisberg, L. Zheng, and M. Zijlema (2013), Gulf of Mexico hurricane wave simulations using SWAN: Bulk formula-based drag coefficient sensitivity for Hurricane Ike, Journal of Geophysical Research: Oceans, 118(8), 3916-3938, doi:10.1002/jgrc.20283.

Hwang, P. A. (2005), Temporal and spatial variation of the drag coefficient of a developing sea under steady wind-forcing, Journal of Geophysical Research: Oceans, 110(C7), doi:10.1029/2005JC002912.

Hwang, P. A., and D. W. Wang (2004), Field Measurements of DurationLimited Growth of Wind-Generated Ocean Surface Waves at Young Stage of Development*, Journal of Physical Oceanography, 34(10), 2316-2326, doi:10.1175/1520-0485(2004)034<2316:FMODGO>2.0.CO;2. 
Janssen, P. A. E. M. (1991), Quasi-linear Theory of Wind-Wave Generation Applied to Wave Forecasting, Journal of Physical Oceanography, 21(11), 1631-1642, doi:10.1175/1520-0485(1991)021<1631:QLTOWW>2.0.CO;2.

Janssen, P. A. E. M., P. Lionello, and L. Zambresky (1989), On the Interaction of Wind and Waves, Philosophical Transactions of the Royal Society A: Mathematical, Physical and Engineering Sciences, 329(1604), 289-301, doi:10.1098/rsta.1989.0077.

Jensen, R. E., V. J. Cardone, and A. Cox (2006), Performance of third generation wave models in extreme hurricanes, 9th International Wind and Wave Workshop, 54, 258.

Kahma, K. K., and C. J. Calkoen (1992), Reconciling Discrepancies in the Observed Growth of Wind-generated Waves, Journal of Physical Oceanography, 22(12), 13891405, doi:10.1175/1520-0485(1992)022<1389:RDITOG >2.0.CO;2.

Komen, G. J., K. Hasselmann, and K. Hasselmann (1984), On the Existence of a Fully Developed Wind-Sea Spectrum, Journal of Physical Oceanography, 14(8), 1271-1285, doi:10.1175/1520-0485(1984)014<1271:OTEOAF>2.0.CO;2.

Komen, G. J., L. Cavaleri, M. Donelan, K. Hasselmann, S. Hasselmann, and P. A. E. M. Janssen (1996), Dynamics and Modelling of Ocean Waves, 532 pp., Cambridge University Press.

Kudryavtsev, V. N., V. K. Makin, and B. Chapron (1999), Coupled sea surface-atmosphere model: 2. Spectrum of short wind waves, Journal of Geophysical Research: Oceans, 104(C4), 7625-7639, doi:10.1029/1999JC900005.

Leckler, F., F. Ardhuin, J. F. Filipot, and A. Mironov (2013), Dissipation source terms and whitecap statistics, Ocean Modelling, 70, 62-74, doi:10.1016/j.ocemod.2013.03.007.

Makin, V. K., and C. Mastenbroek (1996), Impact of waves on air-sea exchange of sensible heat and momentum, Boundary-Layer Meteorology, 79(3), 279-300, doi:10.1007/BF00119442.

Makin, V. K., V. N. Kudryavtsev, and C. Mastenbroek (1995), Drag of the sea surface, Boundary-Layer Meteorology, 73(1-2), 159-128, doi:10.1007/BF00708935.

Makin, V. K., H. Branger, W. L. Peirson, and J. P. Giovanangeli (2007), Stress above Wind-Plus-Paddle Waves: Modeling of a Laboratory Experiment, Journal of Physical Oceanography, 37(12), 2824-2837, doi:10.1175/2007JPO3550.1.

Miles, J. W. (1957), On the generation of surface waves by shear flows, Journal of Fluid Mechanics, 3(02), 185, doi:10.1017/S0022112057000567. 
Moon, I. J., T. Hara, I. Ginis, S. E. Belcher, and H. L. Tolman (2004), Effect of surface waves on air-sea momentum exchange. Part I: Effect of mature and growing seas, Journal of the Atmospheric Sciences, 61(19), 2321-2333, doi:10.1175/1520-0469(2004)061<2321:EOSWOA >2.0.CO;2.

Moon, I. J., J. I. Kwon, J. C. Lee, J. S. Shim, S. K. Kang, I. S. Oh, and S. J. Kwon (2009), Effect of the surface wind stress parameterization on the storm surge modeling, Ocean Modelling, 29(2), 115-127, doi:10.1016/j.ocemod.2009.03.006.

Pierson, W. J. J., and L. Moskowitz (1964), A Proposed Spectral Form for Fully Developed Wind Seas Based on the Similarity Theory of S. A. Kitaigorodskii, Journal of Geophysical Research, 69(24), 5181-5190, doi:10.1029/JZ069i024p05181.

Plant, W. J. (1982), A relationship between wind stress and wave slope, Journal of Geophysical Research: Oceans, 87(C3), 1961-1967, doi:10.1029/JC087iC03p01961.

Reichl, B. G., T. Hara, and I. Ginis (2014), Sea state dependence of the wind stress over the ocean under hurricane winds, Journal of Geophysical Research: Oceans, 119(1), 30-51, doi:10.1002/2013JC009289.

Snyder, R. L., Dobson, F. W., Elliott, J. A., and Long, R. B. (1981), Array measurements of atmospheric pressure fluctuations above surface gravity waves., Journal of Fluid Mechanics, 102, 1-59.

Soloviev, A. V., R. Lukas, M. A. Donelan, B. K. Haus, and I. Ginis (2014), The airsea interface and surface stress under tropical cyclones., Scientific reports, 4, 5306, doi:10.1038/srep05306.

Sørensen, O. L. E. R., H. Kofoed-Hansen, M. Rugbjerg, and L. S. Sørensen (2004), Using an Unstructured Finite Volume Technique, Proceedings of the 29th Intern. Conf. on Coastal Eng.

Taylor, P. K., and M. J. Yelland (2001), The Dependence of Sea Surface Roughness on the Height and Steepness of the Waves, Journal of Physical Oceanography, 31(2), 572-590, doi:10.1175/1520-0485(2001)031<0572:TDOSSR>2.0.CO;2.

The SWAN Team (2015), USER MANUAL SWAN - Cycle III version 41.01AB, Cycle, p. 126.

Tolman, H. L., and D. Chalikov (1996), Source Terms in a Third-Generation Wind Wave Model, Journal of Physical Oceanography, 26(11), 2497-2518, doi:10.1175/1520-0485(1996)026<2497:STIATG >2.0.CO;2. 
van Vledder, G. P. (2006), The WRT method for the computation of non-linear four-wave interactions in discrete spectral wave models, Coastal Engineering, 53(2-3), 223-242, doi:10.1016/j.coastaleng.2005.10.011.

van der Westhuysen, A. J., M. Zijlema, and J. A. Battjes (2007), Nonlinear saturationbased whitecapping dissipation in SWAN for deep and shallow water, Coastal Engineering, 54(2), 151-170, doi:10.1016/j.coastaleng.2006.08.006.

Wu, J. (1982), Wind-stress coefficients over sea surface from breeze to hurricane, Journal of Geophysical Research: Oceans, 87(C12), 9704-9706. doi:10.1029/JC087iC12p09704.

Yan, L. (1987), An improved wind input source term for third generation ocean wave modeling, KNMI, Report 87-8, 27 pp.

Young, I. (1999), Wind Generated Ocean Waves Chapter 5 Fetch and duration limited growth, Elsevier Science, pp. 83-131, doi:10.1016/S1571-9952(99)80007-5.

Young, I. R., and A. V. Babanin (2006), Spectral Distribution of Energy Dissipation of Wind-Generated Waves due to Dominant Wave Breaking, Journal of Physical Oceanography, 36(3), 376-394, doi:10.1175/JPO2859.1.

Zijlema, M., G. P. Van Vledder, and L. H. Holthuijsen (2012), Bottom friction and wind drag for wave models, Coastal Engineering, 65, 19-26, doi:10.1016/j.coastaleng.2012.03.002.

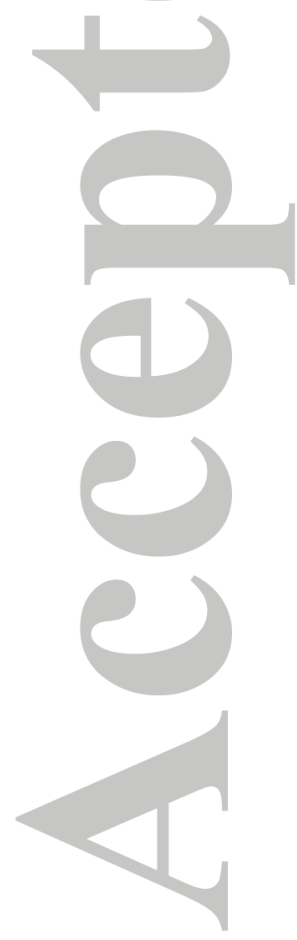

